\title{
Neuronal and synaptic plasticity in the visual thalamus in mouse models of glaucoma.
}

Running title: dLGN plasticity in mouse glaucoma.

Authors: Matthew J. Van Hook ${ }^{1,2,{ }^{*}}$, Corrine Monaco ${ }^{2,3}$, Jennie C. Smith ${ }^{1}$

Affiliations:

${ }^{1}$ Truhlsen Eye Institute, Department of Ophthalmology \& Visual Sciences, University of Nebraska Medical Center, Omaha, NE 68198

${ }^{2}$ Department of Cellular \& Integrative Physiology, University of Nebraska Medical Center, Omaha, NE 68198

${ }^{3}$ Department of Obstetrics \& Gynecology, Olson Center for Women's Health, University of Nebraska Medical Center, Omaha, NE 68198

${ }^{*}$ Corresponding Author:

Matthew J. Van Hook

Department of Ophthalmology \& Visual Sciences, University of Nebraska Medical Center 985840 Nebraska Medical Center, Omaha, NE 68198-5840, USA

matt.vanhook@unmc.edu

Word count: 8,882

Figure count: 8

\section{Funding:}

National Institutes of Health/National Eye Institute R01 EY030507

BrightFocus Foundation National Glaucoma Research Program: G2017027

National Institutes of Health Grant P30 GM110768 (Molecular Biology of Neurosensory Systems COBRE grant).

University of Nebraska Collaboration Initiative Seed Grant.

Conflict of Interest Disclosure: The authors declare that the research was conducted in the absence of any commercial or financial relationships that could be construed as a potential conflict of interest.

\section{Acknowledgements:}

Elizabeth Bierlein and Ashish Bhandari for comments on the manuscript.

\section{Author Contributions:}

MJVH: Funding, experimental design, conducting experiments, analyzing data, writing manuscript

CM: conducting experiments, analyzing data

JCS: conducting experiments, analyzing data 


\section{4}

45

46

47

48

49

50

51

52

53

54

\section{Abstract}

Homeostatic plasticity plays important roles in regulating synaptic and intrinsic neuronal function to stabilize output following perturbations to circuit activity. In glaucoma, a neurodegenerative disease of the visual system commonly associated with elevated intraocular pressure (IOP), early disease is associated with altered synaptic inputs to retinal ganglion cells (RGCs), changes in RGC intrinsic excitability, and deficits in optic nerve transport and energy metabolism. These early functional changes can precede RGC degeneration and are likely to alter RGC outputs to their target structures in the brain and thereby trigger homeostatic changes in synaptic and neuronal properties in those brain regions. In this study, we sought to determine whether and how neuronal and synaptic function is altered in the dorsal lateral geniculate nucleus (dLGN), an important RGC projection target in the thalamus, and how functional changes relate to IOP. We accomplished this using patch-clamp recordings from thalamocortical (TC) relay neurons in the dLGN in two established mouse models of glaucoma the DBA/2J (D2) genetic mouse model and an inducible glaucoma model with intracameral microbead injections to elevate IOP. We found that the intrinsic excitability of TC neurons was enhanced in D2 mice and these functional changes were mirrored in recordings of TC neurons from microbead-injected mice. Notably, many neuronal properties were correlated with IOP in older D2 mice, but not younger D2 mice or microbead-injected mice. The frequency of miniature excitatory synaptic currents (mEPSCs) was reduced in both ages of D2 mice, and vGlut2 staining of RGC synaptic terminals was reduced in an IOP-dependent manner in older D2 mice. Among D2 mice, functional changes observed in younger mice without elevated IOP were distinct from those observed in older mice with elevated IOP and RGC degeneration, suggesting that glaucoma-associated changes to neurons in the dLGN might represent a combination of stabilizing/homeostatic plasticity at earlier stages and pathological dysfunction at later stages.

\section{Keywords}

Glaucoma, lateral geniculate nucleus, thalamus, DBA/2J mouse, microbead occlusion model, ocular hypertension, intrinsic excitability, synaptic transmission 


\section{Introduction}

Changes in synaptic and neuronal function are hallmarks of numerous neurological and neurodegenerative diseases (Wishart et al., 2006; Hall et al., 2015; Wang et al., 2016, 2017; Bae and Kim, 2017; Kim et al., 2017). In many cases, these are likely to be the result of early-stage homeostatic plasticity, which modulates neuronal response properties to maintain firing rate and compensate for altered circuit activity (Turrigiano, 2012; Wondolowski and Dickman, 2013). Such homeostatic modulation is accomplished by scaling presynaptic neurotransmitter release mechanisms, alterations in the balance of excitation and inhibition, modulation of postsynaptic neurotransmitter receptor complement and function, and tuning of intrinsic neuronal excitability and spiking behavior. In cases of disease or injury, homeostasis can make up for circuit dysfunction, but only to a point, after which disease processes are likely to overwhelm homeostasis and trigger unchecked dysfunction and degeneration (Orr et al., 2020). Understanding mechanisms of neuronal homeostasis in disease and injury is likely to provide insights into endogenous mechanisms with neuroprotective potential. Moreover, understanding pathological alterations in function is critical for shedding light on the timeline and mechanisms of neuronal loss and disease pathogenesis.

Glaucoma is a blinding neurodegenerative disease that strikes at retinal ganglion cells (RGCs), the output neurons of the retina (Calkins, 2012; Weinreb et al., 2014). It is commonly associated with elevated eye pressure, which damages RGC axons at the optic nerve head and culminates in the degeneration of their axon projections to visual regions of the brain and apoptotic loss of cell bodies in the retina. However, glaucoma-associated changes to visual function are likely the result of more than RGC and axonal degeneration, as cell loss is preceded by numerous changes in the structure and function of RGC-associated circuits. Within the retina, for instance, pressure elevation upregulates $\mathrm{Na}^{+}$channel expression and spiking behavior of RGCs, alters the size and complexity of their dendritic fields, changes receptive field properties, leads to changes in post-synaptic receptor composition, and alters the responses of upstream retinal circuits (Della Santina et al., 2013, 2013; Frankfort et al., 2013; Wang et al., 2014; Pang et al., 2015; Ou et al., 2016; Bhandari et al., 2019; McGrady et al., 2020; Sladek and Nawy, 2020). Within the optic projection and at RGC output sites in the brain, eye pressure and glaucomatous injury lead to alterations in optic nerve glial function and energy demands (Baltan et al., 2010; Inman and Harun-Or-Rashid, 2017; Jassim et al., 2019; Cooper et al., 2020), RGC axon terminal swelling and atrophy (Smith et al., 2016), changes in axon terminal mitochondrial health (Smith et al., 2016), altered synaptic vesicle release properties (Bhandari et al., 2019), and post-synaptic neuronal dendritic remodeling and somatic atrophy (Gupta and Yücel, 2003; Gupta et al., 2007, 2009, Liu et al., 2011, 2014; Bhandari et al., 2019). It is likely that such changes represent a mix of both homeostatic attempts at preserving retinal output fidelity and pathological alterations in neural function in glaucoma. Overall, the relative timing, balance, and interplay of these two possible processes remains unknown.

The goal of this study was to test the hypothesis that glaucoma progression triggers changes in neuronal and synaptic function in the dorsal lateral geniculate nucleus (dLGN), a major RGC projection target in the thalamus that underlies conscious, image-forming vision by receiving and processing $R G C$ signals and relaying them to the primary visual cortex (Kerschensteiner and Guido, 2017; Seabrook et al., 2017). Long considered a simple relay structure, recent evidence has highlighted how changes in visual activity can alter dLGN 
synapses and neuronal function (Rose and Bonhoeffer, 2018). For instance, the maturation of neuronal excitability, dendritic structure, and synaptic transmission is regulated by visual experience and retinal inputs during development and young adulthood (Hooks and Chen, 2006; Hong and Chen, 2011; Seabrook et al., 2013; Louros et al., 2014; El-Danaf et al., 2015; Liang and Chen, 2020). Moreover, several studies have documented examples of functional alterations occurring in dLGN neurons and synapses in response to altered sensory input and in cases of disease and injury (Krahe and Guido, 2011; Araújo et al., 2017; Sommeijer et al., 2017; Rose and Bonhoeffer, 2018; Bhandari et al., 2019). This raises the possibility that RGC injury and dysfunction occurring in glaucoma can trigger compensatory homeostatic plasticity in dLGN synapses and neurons.

Therefore, we set out to determine whether and how changes to neuronal function relate to eye pressure and glaucomatous RGC degeneration to shed light on the links between eye pressure, neuronal homeostasis, and dysfunction in glaucoma. This was accomplished by using two complementary mouse models of glaucoma and probing for structural and functional alterations to neurons and synapses in the dLGN. Ultimately, we find changes in excitatory synaptic transmission onto the principal dLGN relay neurons. Additionally, glaucoma enhances their excitability in a manner associated with eye pressure at a later phase of the disease. At a later time point, we find RGC synaptic terminal loss associated with IOP and atrophy of neuronal cell bodies in the dLGN, which are likely to be signs of later-stage disease pathology. This implies that the dLGN in glaucoma is characterized by a potentially homeostatic modulation of function occurring early in the disease process, followed by later alterations and degeneration that are linked to disease severity. 


\section{Materials and Methods}

145

146

147

148

149

150

151

152

153

154

155

156

157

158

159

160

161

162

163

164

165

166

167

168

169

170

171

172

173

174

175

176

177

178

179

180

181

182

183

184

185

186

187

\section{Animals}

Animal protocols were approved by the Institutional Animal Care and Use Committee at the University of Nebraska Medical Center. DBA/2J (D2; Jax\# 000671) were used as an inherited model of glaucoma (John et al., 1998; Libby et al., 2005; Howell et al., 2007) and bred in-house or purchased from Jackson Labs. A strain-matched control line that contains a wild allele of the Gpnmb gene and does not develop elevated eye pressure or glaucoma was used as a control (DBA/2J ${ }^{\text {Gpnmb+/SjJ }}$; D2-control; Jax\# 007048) (Howell et al., 2007). For microbead injection experiments, we used mice produced as a cross of Opn4 ${ }^{\text {Cre/Cre }}$ (Ecker et al., 2010) and Ai32 (Jax \#024109) (Madisen et al., 2012) lines (Opn4-Cre;Ai32) (Bhandari et al., 2019). Mouse were housed in a 12/12 hour light/dark cycle and provided with food and water ad libitum.

\section{Microbead occlusion model}

To induce ocular hypertension, fluorescently-tagged polystyrene microspheres (10 micron, Invitrogen F8836) were bilaterally injected into the anterior chambers of Opn4 ${ }^{\mathrm{Cre}}$;Ai32 mice at 6-8 weeks of age (Sappington et al., 2010; Calkins et al., 2018; Bhandari et al., 2019). This procedure was performed under isoflurane anesthesia and following instillation of anesthetic eye drops ( $0.5 \%$ proparacaine, Akorn, Lake Forest, IL). Pupils were dilated with $1 \%$ tropicamide eye drops. In total a small volume of beads $(\sim 1-2 \mu \mathrm{L})$ at a concentration of $\sim 14 \times 10^{6}$ beads $/ \mathrm{mL}$ was injected using a glass micropipette.

\section{Intraocular pressure measurements}

Intraocular pressure (IOP) was monitored using a Tonolab rebound tonometer (iCare, Vantaa, Finland) in mice lightly anesthetized with isoflurane, as we have described previously (Bhandari et al., 2019). IOP was measured approximately monthly in D2 and D2-control mice beginning around 2-4 months of age and was measured prior to and at 2 days, 1, 2, and 4 weeks post-injection for microbead-injected mice. For assessing the cumulative injury effects of IOP in D2 mice, we calculated a "3-month cumulative IOP", which for a given mouse, is the sum of monthly IOP measurements taken over a three month-span (IOP measurements at 7, 8 and 9 months of age) and averaged across the two eyes. For microbead injected mice, we calculated a cumulative $\triangle$ IOP over baseline for each mouse as the average across the two eyes of 1 week, 2 , week, and 4-week post-injection IOP measurements over the pre-injection baseline.

\section{Brain slice patch-clamp electrophysiology}

250-micron thick coronal brain slices containing the dLGN were acutely prepared using the "protected recovery" method (Ting et al., 2014, 2018), as we have described previously (Bhandari et al., 2019; Van Hook, 2020). Following euthanasia by $\mathrm{CO}_{2}$ asphyxiation and cervical dislocation, brains were submerged in a slush of artificial cerebrospinal fluid (aCSF) comprised of (in mM) $128 \mathrm{NaCl}, 2.5 \mathrm{KCl}, 1.25 \mathrm{NaH}_{2} \mathrm{PO}_{4}, 24 \mathrm{NaHCO}_{3}, 12.5$ glucose, $2 \mathrm{CaCl}_{2}$, and $2 \mathrm{MgSO}_{4}$ and continuously bubbled with a mixture of $5 \% \mathrm{CO}_{2}$ and $95 \% \mathrm{O}_{2}$. Slices were prepared on a vibrating microtome (Leica VT1000S) and hemisected through the midline. Slices were then incubated for $\sim 12$ minutes at $33^{\circ} \mathrm{C}$ in an N-methyl-D-glucamine-based solution (in mM: $92 \mathrm{NMDG}, 2.5 \mathrm{KCl}$, $1.25 \mathrm{NaH}_{2} \mathrm{PO}_{4}, 25$ glucose, $30 \mathrm{NaHCO}_{3}, 20 \mathrm{HEPES}, 0.5 \mathrm{CaCl}_{2}, 10 \mathrm{MgSO}_{4}$, 2 thiourea, $5 \mathrm{~L}$-ascorbic 
acid, and 3 Na-pyruvate), after which they were transferred to a solution of room-temperature aCSF and allowed to recover for $>1$ hour prior to beginning recording.

dLGN slices were transferred to a recording chamber on a fixed-stage upright microscope (Olympus BX51-WI) and superfused with aCSF at a rate of $2-4 \mathrm{~mL} / \mathrm{min}$. For recordings from D2 and D2-control mice, the aCSF was warmed to $30-33^{\circ} \mathrm{C}$ using an inline heater. For recordings from microbead-injected mice, experiments were performed at room temperature $\left(\sim 23^{\circ} \mathrm{C}\right)$ and the aCSF was supplemented with 60 microM picrotoxin. Thalamocortical relay (TC) neurons located in the dLGN core ( $>100$ microns from the dorsolateral surface of the dLGN) were targeted for whole-cell recording based on soma size and shape and distinguished from interneurons by the presence of a pronounced low-voltage activated T-type $\mathrm{Ca}^{2+}$ current. For voltage-clamp experiments, the patch pipette solution was comprised of (in mM) 120 Cs-methanesulfonate, 2 EGTA, 10 HEPES, 8 TEA-Cl, 5 ATP-Mg, 0.5 GTP-Na 25 phosphocreatine- $\mathrm{Na}_{2}, 2 \mathrm{QX}-314$ ( $\mathrm{pH}=7.4,275 \mathrm{mOsm}$ ) while for current-clamp experiments, the pipette solution was comprised of (in mM) $120 \mathrm{~K}$-gluconate, $8 \mathrm{KCl}, 2 \mathrm{EGTA}, 10$ HEPES, 5 ATP-Mg, 0.5 GTP-Na 2 , 5 phosphocreatine ( $\mathrm{pH}=7.4,275 \mathrm{mOsm})$. Miniature excitatory post-synaptic currents (mEPSCs) were recorded in the absence of stimulation at a holding potential of $-70 \mathrm{mV}$. TC neuron spiking was evoked using a series of depolarizing current injections ( +40 to $+560 \mathrm{pA}, 500 \mathrm{~ms}$ ) while membrane properties were monitored using hyperpolarizing injections (-20 to $-100,500 \mathrm{~ms})$.

\section{Electrophysiology analysis}

Action potentials from current-clamp experiments were detected and counted using the "event detection" function of Clampfit. Input resistance (Rin) was measured as the slope of a straight line fit to the voltage deflection amplitudes evoked by current stimuli of -20 and $-40 \mathrm{pA}$. Membrane time constant $\left(\tau_{m}\right)$ was measured with a single exponential fit to the voltage deflection evoked by a -20 pA step and was used along with Rin to calculate the membrane capacitance $\left(\mathrm{Cm}=\tau_{\mathrm{m}} / \mathrm{Rin}\right)$. mEPSCs were detected and analyzed using MiniAnalysis software (Synaptosoft, Fort Lee, NJ). For each cell, the first $\sim 100$ detected events were analyzed. Using the same number of events for each recorded cell avoids biasing the cumulative distribution analysis of event amplitude and inter-event intervals. All reported voltages are corrected for a measured $-14 \mathrm{mV}$ liquid junction potential for the K-based pipette solution and a $-10 \mathrm{mV}$ liquid junction potential for the Cs-based solution.

\section{Immunofluorescence staining}

For labeling RGC somata, we performed immunofluorescence staining of flat-mount retinas with a guinea pig-anti-RBPMS antibody (PhosphoSolutions, 1832-RBPMS, 1:500, RRID: $\left.A B \_2492226\right)$ (Rodriguez et al., 2014). Position in the retina was determined by staining with a primary antibody sensitive to S-opsin (rabbit-anti-s-opsin, 1:500, Millipore ABN1660) (Sondereker et al., 2018; Stabio et al., 2018), which is expressed in a gradient along the dorsalventral axis of the retina (Applebury et al., 2000). Retinas were dissected into oxygenated aCSF or Ames solution. Four relieving cuts were made, and the retina was mounted on a nitrocellulose membrane (type AAWB, 0.8 micron pore size, Millipore, Burlington, MA, USA) and fixed by immersion in $4 \%$ paraformaldehyde for 30 mins. Retinas were washed, blocked and permeabilized in a solution of $1 \%$ triton $\mathrm{X}-100,0.5 \%$ DMSO, 5.5\% donkey serum, and $5.5 \%$ 
goat serum for 1 hour before being incubated overnight at $4^{\circ} \mathrm{C}$ in the same solution plus addition of the primary antibodies. Retinas were then washed 6x, blocked/permeabilized again, and incubated with an AlexaFluor 568-conjugated goat-anti-guinea pig and an AlexaFluor 488conjugated donkey-anti-rabbit secondary antibodies for 2 hours at room temperature. After washing $3 x$ in PBS, retinas were removed from the nitrocellulose membranes, mounted on Superfrost Plus slides, and coverslipped with VectaShield Hardset.

For immunofluorescence staining of dLGN sections, mice were euthanized and brains dissected, as described above. After a brief rinse in PBS, they were immersed in $4 \%$ paraformaldehyde for 4 hours after which they were rinsed $3 x$ in PBS and cryoprotected for 1-3 nights by immersion in $30 \%$ sucrose in PBS at $4{ }^{\circ} \mathrm{C}$. Brains were embedded in $3 \%$ agar, cut into 50 micron sections with a Leica VT1000S vibratome, mounted on SuperFrost Plus slides and stored at $-20^{\circ} \mathrm{C}$. After blocking/permeabilization in PBS containing $0.5 \%$ TritonX-100, 5.5\% (donkey and/or goat serum), slices were stained using either a rabbit-anti-vGlut2 primary antibody (1:250, Cedarlane/Synaptic Systems \#135403, RRID: AB_887883) or a combination of guinea pig-anti-NeuN polyclonal antibody (Millipore ABN90, RRID:AB_11205592, 1:500) and rabbit-anti-GAD65/67 polyclonal antibody (1:500, Millipore G5163, RRID: AB_477019) overnight at $4^{\circ} \mathrm{C}$ in a humidified chamber. For staining with the guinea pig primary antibody, we used a blocking solution containing both goat and donkey serum. Secondary antibodies were goat- or donkey-raised AlexaFluor 488 or 568-conjugated antibodies and were used at a concentration of 1:200. Slides were then washed $3 \mathrm{x}$ in PBS followed by $1 \mathrm{x}$ in $\mathrm{dH} 2 \mathrm{O}$ and coverslipped using VectaShield Hardset.

Imaging was performed with a 2-photon microscope with a 20x water-immersion objective (Scientifica) with the laser tuned to $800 \mathrm{~nm}$. vGlut2 images were acquired in frames of $185 \times 185 \mu \mathrm{m}(5.54$ pixels $/ \mu \mathrm{m})$ with $0.5 \mu \mathrm{m}$ z-axis spacing from the dLGN core. Four images per focal plane were averaged and a maximum intensity projection was created from five planes to give an effective z-slice thickness of 2.5 microns. The vGlut2 signal was automatically thresholded and puncta were detected using the Synapse Counter plug-in in ImageJ (Dzyubenko et al., 2016) with a size threshold of $9 \mu \mathrm{m}^{2}$.

For imaging RGCs, RBPMS-stained retinas were imaged in frames of $350 \times 350 \mu \mathrm{m}$ (1.04 pixels $/ \mu \mathrm{m})$. A series of images were acquired through the ganglion cell layer at 1 micron spacing in four quadrants of the central and peripheral retina ( 500 and $1700 \mu \mathrm{m}$ from the optic nerve head, respectively). Each of the four quadrants were identified as temporal, nasal, ventral, or dorsal based on the dorsal-ventral gradient of s-opsin cone labeling (Applebury et al., 2000). Four images per focal plane were averaged for analysis and RGCs were counted using the Cell Counter plug-in in ImageJ.

NeuN and GAD65/67-stained neurons in the dLGN core were imaged in frames of $185 \mathrm{x}$ $185 \mu \mathrm{m}$ (5.54 pixels/ $\mu \mathrm{m}$ ) with 1 micron z-axis spacing. Four images per plane were acquired and averaged for analysis. To measure cross-sectional soma area, NeuN-stained cell bodies were traced by hand in the image plane of each cells' greatest area. After tracing, the regions of interest were superimposed on the GAD65/67 signal and GAD65/67-positive cell bodies were excluded from soma area analysis. 

was assessed using several different approaches. A two-tailed nested t-test was performed using GraphPad Prism 8 for electrophysiology experiments in which multiple cells were recorded from multiple animals, as indicated below. Otherwise, an unpaired two-tailed Student's t-test was used, as indicated. Significance threshold was set at $p<0.05$ for t-tests. Differences in cumulative distributions of mEPSC inter-event intervals, mEPSC amplitudes, vGlut2 punctum sizes, and dLGN TC neuron soma sizes were assessed using a KolmogorovSmirnov (K-S) test in ClampFit 10. For K-S tests, $\mathrm{p}<0.0005$ was considered statistically significant. A linear regression was used to test for correlations of mEPSC, excitability, RGC density, and vGlut2 staining with intraocular pressure. For correlation analysis, the mean values of each parameter for each mouse was used for the fit. A p-value $<0.05$ was considered a statistically significant correlation. 


\section{$\underline{\text { Results }}$}

\section{dLGN TC neuron excitability is enhanced in D2 mice}

To determine whether glaucoma and IOP affect the function of neurons in the dLGN, we made use of the DBA/2J (D2) line of mice. These mice displayed elevated IOP beginning around 7 months of age when compared to a strain-matched control mouse line (DBA/2J ${ }^{G n m b+/ S j J}$; D2control; Figure 1). The IOP elevation was variable in D2 mice and peak IOP within the population (aged 9-10 months) ranged from $11 \mathrm{mmHg}$ to $39 \mathrm{mmHg}$ ( $\mathrm{n}=52$ eyes, 26 mice). This distribution was significantly different than the maximum IOP values from D2-control mice ( $p<0.00001, \mathrm{~K}-\mathrm{S}$ test). At 9 months of age, for instance, IOP was $20.2 \pm 6.2 \mathrm{mmHg}$ (Mean \pm SD; $\mathrm{n}$ = 32 eyes, 16 mice) for D2 compared to $11.9 \pm 2.4$ for 9 month-old D2-control mice $(n=16$ eyes, 8 mice; $p<0.00001)$. This timeline and variability in IOP is consistent with prior studies of D2 mice (John et al., 1998; Libby et al., 2005; Inman et al., 2006).

Glaucoma is triggered by injury to retinal ganglion cell axons, which comprise the optic nerve and are responsible for carrying information to visual centers of the brain. Because of this, we next sought to determine whether D2 mice display changes in the function of neurons in the dLGN, a key RGC projection target for conscious vision, and relate those changes to IOP. To do this, we targeted thalamocortical (TC) relay neurons in the dLGN for whole cell current clamp recording in acute coronal dLGN brain slices (Figure 2). Experiments were performed in slices from D2 and D2-control mice at four and nine months ( $4 \mathrm{~m}$ and $9 \mathrm{~m}$ ) of age in order to compare function at an earlier (pre-ocular hypertension/pre-OHT) and a later (OHT) time point.

When we used depolarizing current injections (500 ms, 40-560 pA; Figure 2B-E), we found that spiking was enhanced in 4-month old $(4 \mathrm{~m})$ D2 mice compared to D2-controls. For instance, a 240 pA current injection evoked $19 \pm 4$ action potentials in D2-control mice $(n=15$ cells, 5 mice) whereas TC neurons from age-matched D2 mice fired $55 \pm 9$ action potentials ( $n=$ 15 cells, 5 mice; $p=0.0016)$. We further quantified the enhanced excitability by measuring the area under the curve (AUC) of the current-spike relationship as well as the half-maximal current stimulus of a Boltzmann fit $\left(I_{50}\right)$ (Figure $2 F \& G$ ). In this analysis, the AUC from $4 m$ D2 cells was elevated ( $31 \pm 3 n A^{*}$ spikes) relative to $D 2$ controls ( $22 \pm 2 n A^{*}$ spikes), although the difference was not significant $(p=0.17)$. The $I_{50}$ was significantly shifted left, from $332 \pm 16 p A$ for D2controls to $244 \pm 17 p A$ for D2 mice $(p=0.0018)$.

When we performed similar experiments with 9m D2 and D2-control mice, the difference in excitability was similar although differences generally did not reach statistical significance. For instance, the AUC was $26 \pm 2 n A^{*}$ spikes in $9 m$ D2-control mice ( $n=13$ cells, 4 mice) and $30 \pm 2 n A^{*}$ spikes in 9m D2 mice ( $n=23$ cells, 6 mice; $\left.p=0.4\right)$. Additionally, the $I_{50}$ was $314 \pm 11$ pA in D2-controls and $254 \pm 13$ in D2's ( $p=0.048)$.

Notably, we did find that there was considerable variability of the spiking in 9m D2 TC neurons relative to D2-controls. For instance, the SD of the $I_{50}$ was 64 pA for $9 \mathrm{~m} \mathrm{D2}$ and $39 \mathrm{pA}$ for D2-control while for AUC, the SD was 9.0 for D2 and 6.9 for D2-control. As shown above, there was also wide variability in D2 mouse IOP values at 9 months. We turned this to our advantage by testing whether AUC and $I_{50}$ were related to the cumulative IOP experienced by the D2 mouse visual system by plotting AUC and $I_{50}$ against the 3-month cumulative IOP (Figure $2 \mathrm{H} \& \mathrm{I})$. When we did this, we found that the AUC positively correlated with cumulative IOP $(p=$ 0.01 ) while the $I_{50}$ negatively correlated with cumulative IOP $(p=0.002)$. In contrast, IOP was 
not elevated in the 4-month old D2 mice and there was no significant correlation of AUC or $I_{50}$ with IOP ( $p>0.05)$. Thus, higher eye pressure in aged D2 mice was associated with greater dLGN TC neuron excitability.

We next sought to probe the cellular mechanisms underlying this change in neuronal excitability (Figure 3) and found that the increase in TC neuron excitability in both $4 \mathrm{~m}$ and $9 \mathrm{~m}$ D2 mice was associated with changes in membrane properties that support increased action potential firing, although the effects were slightly different at each age. At 4m, D2 TC neurons were slightly depolarized relative to D2-controls (D2: $-78.2 \pm 0.7 \mathrm{mV}$; D2-control: $-81.3 \pm 0.6$ $\mathrm{mV} ; \mathrm{p}=0.011$ ), which brings their membrane potential closer to action potential threshold. Additionally, input resistance (Rin), measured with a linear fit to voltage responses to hyperpolarizing current injections (Figure $3 A \& B$ ), was higher in $4 \mathrm{~m}$ D2 mice (D2: $288 \pm 20 \mathrm{M} \Omega$; D2-control: $221 \pm 17 \mathrm{M} \Omega$; $\mathrm{p}=0.018)$. Membrane capacitance $(\mathrm{Cm})$, an electrical measure of cell surface area, was not significantly different between D2 and D2-control at 4 months (D2: 105.2 + 7.1 pF; D2-control: $117.3 \pm 8.0 \mathrm{pF} ; \mathrm{p}=0.27)$.

At 9 months, there were no significant differences in Vrest, Rin, or Cm between D2 and D2-controls. For instance, Vrest was $-77.7 \pm 1 \mathrm{mV}$ for $9 \mathrm{~m} \mathrm{D2}$ and $-79.7 \pm 0.6 \mathrm{mV}$ for D2-controls $(p=0.25)$. Cm was notably lower in D2s $(86.7 \pm 5.4 \mathrm{pF})$ compared to D2-controls $(100.8 \pm 3.9 \mathrm{pF})$, but the difference was not significant $(p=0.27)$. Likewise, Rin appeared elevated in D2's (333 \pm $23 \mathrm{M} \Omega$ ) compared to D2-controls $(262 \pm 17 \mathrm{M} \Omega)$, but not significantly so $(p=0.22)$.

As for AUC and $\mathrm{I}_{50}$, above, we noted that there was considerable variability in Vrest, Rin, and $\mathrm{Cm}$. Therefore, we tested whether there was a correlation of each parameter with IOP in D2 mice (Figure 3F\&G). For mean values of cells recorded from 9m D2 mice, Cm was negatively correlated with IOP $(p=0.025)$, while Rin was positively correlated with IOP $(p=0.011)$. In contrast, there was no significant correlation of Vrest with IOP $(p=0.96)$. Moreover, neither $\mathrm{Cm}$, Rin, nor Vrest were significantly correlated with IOP at 4 months $(p=0.31, p=0.78, p=$ 0.58 , respectively). Thus, in $9 \mathrm{~m} \mathrm{D} 2$ mice, there was an association of several TC neuron parameters with the cumulative IOP such that cells from mice with higher IOP were more excitable, had a higher Rin, and had a lower $\mathrm{Cm}$.

\section{TC neuron soma size is reduced in aged D2 mice.}

A reduction in cell size can contribute to increased Rin and would be consistent with the detected decrease in $\mathrm{Cm}$. We next sought to verify this electrophysiological finding using a parallel anatomical approach in which we identified neuronal cell bodies in the dLGN using a NeuN antibody and measured their cross-sectional area in D2 and D2-control tissue at 4m and $9 \mathrm{~m}$ (Figure 4). GABAergic interneurons were identified by staining with a GAD65/67 antibody and were excluded in order to focus this analysis on the excitatory TC relay neurons in the dLGN. At 4m, there was small shift in the median TC neuron soma area, from $229 \mu \mathrm{m}^{2}$ in D2 control (interquartile range, IQR: $189-274 \mu \mathrm{m}^{2} ; \mathrm{n}=214$ cells from 6 mice) to $196 \mu \mathrm{m}^{2}$ in D2 mice (IQR: $170-234 \mu \mathrm{m}^{2} ; \mathrm{n}=106$ cells from 4 mice; $\mathrm{p}=0.00055, \mathrm{~K}-\mathrm{S}$ test). At $9 \mathrm{~m}$, the difference was much more pronounced, with the median soma area being $233 \mu^{2}$ in D2-controls (IQR: $196-280 \mu \mathrm{m}^{2} ; \mathrm{n}=312$ cells from 10 mice) and the median soma area being $167 \mu \mathrm{m}^{2}$ in D2 mice (IQR: $135-199 \mu \mathrm{m}^{2} ; \mathrm{n}=321$ cells from 9 mice; $\mathrm{p}<0.00001, \mathrm{~K}-\mathrm{S}$ test). This anatomical approach 
supports electrophysiological findings that TC neuron size is reduced in the 9m D2 dLGN and suggests that excitability changes at $9 \mathrm{~m}$, but not $4 \mathrm{~m}$, might be linked to TC neuron atrophy.

\section{Enhancement of TC Neuron excitability in an inducible ocular hypertension (OHT) model.}

To test whether the increase in dLGN TC neuron excitability is a common feature of experimental glaucoma or instead a quirk of the D2 mouse, we next turned to an inducible model in which eye pressure is elevated by injection of microbeads into the anterior chamber (Sappington et al., 2010; Calkins et al., 2018; Bhandari et al., 2019). This led to an approximately $5 \mathrm{mmHg}$ increase in IOP over baseline ( $30 \%$ increase; Figure $5 \mathrm{~A})$, which we have shown previously to trigger changes in the function of retinogeniculate (RG) synapses and TC neuron dendritic structure with minimal RGC loss five weeks after injection (Bhandari et al., 2019).

Here, we performed current clamp recordings to measure neuronal excitability and membrane properties from mice with microbead-induced OHT (Figure 5B), similar to experiments with D2 mice, above. One difference was that experiments with dLGN slices from bead-injected mice were recorded at room temperature rather than warmed, which changes the evoked spiking and membrane properties of TC neurons (Van Hook, 2020). Still, in beadinjected mice, we found that TC neuron excitability was enhanced when compared to TC neurons from saline-injected controls (Figure 5C-E). This was reflected as an increase in the number of action potentials evoked by depolarizing current injection (20-220 pA) and further demonstrated as an increase in the AUC, from $1.2 \pm 0.1 \mathrm{nA} *$ spikes ( $\mathrm{n}=39$ cells, 9 mice) to $2.0 \pm$ $0.2 n A^{*}$ spikes ( $n=24$ cells, 4 mice; $p=0.022$ ). Although there was a trend toward a leftward shift in $\mathrm{I}_{50}$, (saline: $121 \pm 5 \mathrm{pA}$; beads: $108 \pm 5 \mathrm{pA}$ ), the difference was not statistically significant $(p=0.37)$. Additionally, and similar to the $4 m$ D2 mice, there was no significant correlation of either AUC ( $p=0.23)$ or $I_{50}(p=0.22)$ with IOP for bead-injected mice.

We next compared membrane properties, including Vrest, Rin, and Cm, between TC neurons from bead- and saline-injected mice as for D2 and D2-control mice, above (Figure 5F$\mathrm{H})$. We found that Vrest was slightly depolarized in TC neurons from bead-injected mice when compared to controls (beads: $-74.9 \pm 0.6 \mathrm{mV}, \mathrm{n}=24$ cells, 5 mice; saline: $-80.9 \pm 0.8 \mathrm{mV}, \mathrm{n}=39$ cells, 9 mice; $p=0.044)$. Additionally, Rin was elevated in bead-injected mice relative to salineinjected controls (beads: $443 \pm 20 \mathrm{M} \Omega$; saline: $328 \pm 14 \mathrm{M} \Omega ; \mathrm{p}=0.0036$ ). There was a trend toward a reduced $\mathrm{Cm}$ (beads: $121 \pm 4 \mathrm{pF}$; saline: $138 \pm 5 \mathrm{pF}$ ), but the difference was not significant $(p=0.22)$. Also, similar to the $4 \mathrm{~m} \mathrm{D2}$ mice, there was no significant correlation of Vrest $(p=0.34)$, Rin $(p=0.59)$, or $C m(p=0.40)$ with IOP in microbead-injected mice.

\section{Reduced mEPSC frequency in D2 mice}

We have previously shown that IOP elevation in the microbead model leads to a reduction in the frequency of miniature excitatory post-synaptic currents (mEPSCs) recorded from dLGN TC neurons (Bhandari et al., 2019). Therefore, we next used whole-cell voltageclamp recordings of dLGN TC neurons from $4 \mathrm{~m}$ and 9m D2 mice to probe whether and how excitatory inputs are altered in these mice as well (Figure 6). For $4 \mathrm{~m}$ mice (Figure 6A-C), we found that mEPSC amplitude was similar in D2 and D2-control mice (D2-control: $8.3 \pm 0.6 \mathrm{pA}, \mathrm{n}$ $=12$ cells, 5 mice; D2: $9.2 \pm 0.7 p A, n=11$ cells, 4 mice; $p=0.52)$. mEPSCs arising from cortical inputs are slower than those from RGC inputs due to their concentration at more distal dendritic sites and consequent dendritic filtering (Williams and Mitchell, 2008). Shifts in relative 
proportions of cortical-vs-retinal inputs can be reflected in changes in the mEPSC decay kinetics as occurs in monocular deprivation (Krahe and Guido, 2011). However, we did not observe any significant shift in mEPSC decay time constant in 4m TC neurons (D2-control: $2.1 \pm 0.2$; D2: $2.3 \pm$ $0.3 \mathrm{~ms} ; \mathrm{p}=0.74)$. The mEPSC frequency at 4 months was slightly reduced (D2-control: $19.7 \pm 2.7$ $\mathrm{Hz}$; D2: $13.0 \pm 2.3 \mathrm{~Hz}$ ). Although the difference was not significant when assessed with a nested t-test $(p=0.22)$, the distribution of inter-event intervals was significantly different between D2control and D2 ( $p<0.00001, \mathrm{~K}-\mathrm{S}$ test).

At $9 \mathrm{~m}$ (Figure $6 \mathrm{D}-\mathrm{F}), \mathrm{mEPSC}$ amplitude was also similar between D2 and D2-control mice (D2-control: $9.8+0.6 \mathrm{pA}, \mathrm{n}=15$ cells, 4 mice; $\mathrm{D} 2: 9.3 \pm 0.5 \mathrm{pA}, \mathrm{n}=18$ cells, 6 mice; $\mathrm{p}=$ $0.56)$. Additionally, the $m E P S C$ decay time constants were not significantly different at $9 \mathrm{~m}$ (D2control: $1.98 \pm 0.09 \mathrm{~ms} ; \mathrm{D} 2: 1.86 \pm 0.11 \mathrm{~ms} ; \mathrm{p}=0.84)$. mEPSC frequency was significantly lower in 9m D2 mice compared to D2-controls (D2-control: $28 \pm 3.3 \mathrm{~Hz}$; D2: $14.3 \pm 2.1 \mathrm{~Hz} ; \mathrm{p}=0.0009$ ). This was also reflected as a significant shift in the cumulative distributions of inter-event intervals ( $p<0.00001, \mathrm{~K}-\mathrm{S}$ test). In contrast to our findings with excitability and membrane properties, there was no significant correlation of mEPSC frequency with the three-month cumulative IOP $\left(R^{2}=0.48 ; p=0.13\right)$.

Loss of RGC axon terminals in the dLGN of D2 mice

Prior studies have indicated that RGC axon terminals in the superior colliculus (SC) are lost fairly late in disease in DBA/2J and microbead-injected mice and that terminal loss is preceded by swelling followed by atrophy (Crish et al., 2010; Smith et al., 2016). Additionally, we have shown that five weeks of a relatively modest and sustained OHT triggered by anterior chamber microbead injections does not have any effect on RGC axon terminal size or density in the dLGN (Bhandari et al., 2019).

Next, we sought to determine whether the size or density of RGC axon terminals, stained with an antibody raised against vGlut2, which is a selective label for RGC axon terminals in the dLGN, were altered in D2 mice at young age $(4 \mathrm{~m})$ and in older mice $(9 \mathrm{~m})$ with elevated eye pressure (Figure 7). In sections from $4 \mathrm{~m}$ D2 mice (Figure 7A\&B), we found that vGlut2 punctum density was similar to D2-control mice (D2: $11.2 \pm 0.8$ puncta/1000 $\mu \mathrm{m}^{2}, \mathrm{n}=4 \mathrm{mice}$; D2-control: $11.9 \pm 0.2$ puncta/1000 $\mu \mathrm{m}^{2}, \mathrm{n}=6$ mice; $\left.\mathrm{p}=0.48\right)$. We found no evidence for RGC axon terminal atrophy or swelling, as punctum size was similar in controls and D2 (D2: $19.0 \pm$ $0.4 \mu \mathrm{m}^{2}$; D2-control; $18.3 \pm 0.2 \mu \mathrm{m}^{2}, \mathrm{p}=0.21$ ). Further supporting this, the cumulative distribution of vGlut2 punctum size was similar in $4 \mathrm{~m} \mathrm{D2}$ and D2-control mice ( $p=0.18, \mathrm{~K}-\mathrm{S}$ test).

Similar to results at 4 months of age, there was no change in vGlut2 punctum size at $9 \mathrm{~m}$ (D2: $20.8 \pm 0.44 \mu \mathrm{m}^{2}, \mathrm{n}=10$; D2-control: $21 \pm 0.3 \mu \mathrm{m}^{2}, \mathrm{n}=10 ; \mathrm{p}=0.72$; Figure 7C\&D). Likewise, the cumulative distribution of vGlut2 punctum size was similar ( $p=0.82, \mathrm{~K}-\mathrm{S}$ test). Although punctum size was unchanged, vGlut2 density was significantly reduced in D2 mice compared to controls (Figure 7D; D2: $7.8 \pm 1.2$ puncta/1000 $\mu \mathrm{m}^{2}$; D2-control: $11.2 \pm 0.5$ puncta/1000 $\mu \mathrm{m}^{2} ; \mathrm{p}$ $=0.011$ ). Notably, there was considerable variability in vGlut2 punctum density, with a range of 2.4-11.4 puncta/1000 $\mu \mathrm{m}^{2}$ in D2 compared to 8.5-13.5 puncta/1000 $\mu^{2}$ in controls. To test whether the diversity in vGlut2 density in D2 mice might be related to IOP, we tested for correlation of vGlut2 punctum density with the three-month cumulative IOP (Figure 7E). Indeed, vGlut2 density was negatively correlated with the three-month cumulative IOP $(p=$ 
465
0.027), suggesting that a greater loss of RGC axon terminals is associated with a higher cumulative IOP in $9 \mathrm{~m}$ D2 mice.

\section{Eye-pressure-associated RGC loss in D2 mice.}

Although early changes to the structure and function of RGCs, their axons, and their projection targets in the brain are likely to contribute to visual impairment in glaucoma, RGC degeneration is thought to be the major cause of irreversible vision loss. Therefore, we sought to determine the differences in RGC degeneration in D2 mice at $4 \mathrm{~m}$ and $9 \mathrm{~m}$ of age and relate RGC degeneration to IOP in order to have a marker of glaucoma severity as it relates to IOP, mouse age, and the functional changes to synapses and TC neuron spiking behavior in the dLGN. To accomplish this, we labeled RGCs by immunofluorescence staining for RBPMS, a selective RGC marker and counted RGCs to determine their density in four quadrants of the central and peripheral retina (Figure 8 ).

At $4 m$ (Figure $8 A \& B$ ), we found that there was no significant reduction in RGC density in D2 mice compared to D2-controls in either central or peripheral retina (D2: $n=8$ retinas; D2control: $n=7$ retinas). Rather, in the central retina, the RGC density in D2 mice was slightly higher than RGC density in D2-controls. In peripheral retina, however, there was no significant difference between D2- and D2-control RGC density in any of the four quadrants. At $9 \mathrm{~m}$, however, RGC density was significantly lower in D2 than D2-controls (D2: $n=19$ retinas; D2control $n=12$ retinas). This was the case in both central retina and peripheral retina.

Across the retina, there was more variability in the RGC density in D2 mice compared to D2-controls at $9 \mathrm{~m}$ (Figure 8C-F). For instance, the standard deviation of RGC densities across four quadrants in central and peripheral retina in D2-control mice was 289 cells $/ \mathrm{mm}^{2}$ while it was 599 cells $/ \mathrm{mm}^{2}$ for age-matched D2-mice. We then tested whether the differences in RGC density were associated with IOP by calculating RGC survival as \% of control RGC density and testing for correlation of RGC survival across the entire retina with the three-month cumulative IOP. Indeed, RGC survival was negatively correlated with 3-month cumulative IOP $(p=0.0068)$, supporting a relationship between eye pressure and RGC loss in 9m D2 mice. 


\section{Discussion}

In this study, we identify functional changes to the TC relay neurons and their synaptic inputs in the dLGN of DBA/2J mice, a widely-used and established rodent model of inherited glaucoma. Specifically, we find in younger D2 mice that do not have any detectable OHT or RGC loss, TC neurons more readily fire action potentials in response to depolarizing current stimuli and that this is associated with a slight depolarization and increase in neuronal input resistance. TC neuron excitability and membrane parameters were only subtly different from controls in 9month D2 mice. There was much more variability in neuronal excitability and passive membrane properties at $9 \mathrm{~m}$ and these parameters correlated with D2 mouse IOP. In mice with a modest $\mathrm{OHT}$ triggered by anterior chamber microbead injection, TC neuron excitability was also increased in a manner that resembled the 4-month D2 mouse population in that it was associated with a small depolarization and increase in Rin without significant change in $\mathrm{Cm}$. Moreover, excitability and passive membrane properties (AUC, $\mathrm{I}_{50}, \mathrm{Cm}$, Rin) did not correlate with IOP in microbead-injected mice, similar to $4 \mathrm{~m}$ D2 mice.

With the differences in functional effects observed in 4m and 9m D2 mice as well as in consideration of the effects in microbead-injected mice, we suggest that the pattern of functional changes in the dLGN represents distinct, although potentially overlapping, phases of glaucoma's effects. At 4m, the effects are likely to represent homeostatic plasticity (Turrigiano, 2011, 2012; Crish and Calkins, 2015); there was no detectable RGC loss at this time point and IOP remained low, similar to control mice. However, other studies have documented that functional changes can occur in the visual pathway of D2 mice at this age and earlier including diminishment of optic nerve transport, remodeling of astrocytes in the optic nerve, and tau hyperphosphorylation (Crish et al., 2010; Dengler-Crish et al., 2014; Crish and Calkins, 2015; Cooper et al., 2016; Wilson et al., 2016). Thus, the enhanced excitability in 4m D2 mice might represent functional homeostasis triggered as a downstream consequence of compromised optic nerve health and disrupted signal transmission from RGCs.

Indeed, homeostatic upregulation of intrinsic excitability has been documented in response to altered visual input in visual cortex (Maffei and Turrigiano, 2008; Lambo and Turrigiano, 2013). OHT also alters RGC spike output, causing an early increase in excitability due to changed $\mathrm{Na}^{+}$channel expression (Risner et al., 2018, 2020; McGrady et al., 2020). Other studies have documented diminishment of spontaneous and light-evoked RGC spike output occurring at different times with different IOP manipulations (Della Santina et al., 2013; Ou et al., 2016; Risner et al., 2018; Bhandari et al., 2019). Changes in RGC spike output might alter depolarization-triggered CREB activity in TC neurons (Pham et al., 2001; Guido, 2008; Krahe et al., 2012; Dilger et al., 2015). Altering RGC spiking might also influence activity-dependent release of the neurotrophin BDNF, which is important in glaucoma pathology (Crish et al., 2013; Domenici et al., 2014; Gupta et al., 2014; Dekeyster et al., 2015; Valiente-Soriano et al., 2015), regulates development of retinal ganglion cells and their brain projections (Marshak et al., 2007; Cohen-Cory et al., 2010; Nikolakopoulou et al., 2010), and is involved in homeostatic and experience-dependent plasticity of cortical neurons (Rutherford et al., 1998, 1998; Desai et al., 1999; Bracken and Turrigiano, 2009).

In contrast to our findings at $4 \mathrm{~m}$, there was a notable correlation of neuronal excitability, including spiking parameters and passive membrane properties with IOP in 9m mice. In these cases, higher IOP was associated with increased TC neuron excitability in the 
dLGN. Moreover, RGC density was significantly reduced across the retina by $9 \mathrm{~m}$ and we found that higher IOP was also associated with lower RGC survival. At this time point, we observed electrophysiological signatures of reduced TC neuron size and confirmed the TC neuron atrophy by measurements of TC neuron soma area. This is consistent with other studies of retinal projection targets in fairly late-stage glaucoma from human patients and primate and rodent animal studies which have also documented neuronal atrophy in the dLGN and SC (Yücel et al., 2001; Gupta et al., 2007, 2009). Thus, the pattern of functional changes we observed might represent a shift from pre-degenerative homeostasis to pathological dysfunction associated with RGC somatic and axon terminal degeneration (Orr et al., 2020).

Probing synaptic function, we also found in both younger and older D2 mice that the excitatory synaptic input onto dLGN TC neurons was reduced, as indicated by a reduction in MEPSC frequency. There was no change in mEPSC amplitude, suggesting that the post-synaptic AMPA receptor population was stable at excitatory synapses onto TC neurons. Moreover, in older mice, there was a reduction in the density of vGlut2-labeled RGC axon terminals in the dLGN in a manner that correlated with IOP such that higher eye pressure was associated with a greater terminal loss.

Previous studies of the superior colliculus of D2 mice have reported that RGC axon terminals survive until fairly late in the disease and only degenerate well after RGC loss (Crish et al., 2010; Smith et al., 2016; Wilson et al., 2016). In our sample of 9m D2 mice, we found that RGC axon terminals were lost in an IOP-dependent manner. We did not see evidence of either RGC axon terminal atrophy or swelling, as has been reported in ultrastructural studies of the SC (Smith et al., 2016). Several possibilities could account for this difference. First, it is possible is that, unlike in the SC, RGC terminals in the dLGN do not exhibit phases of swelling and atrophy prior to degeneration. This could represent a difference between these two visual structures, possibly resulting from relative proximity of each structure to the retina, which is known to be associated with differential effects on the optic projection (Crish et al., 2010; Calkins, 2012). Alternatively, light microscopy as we implemented it might be too coarse of an imaging modality to detect subtle changes in RGC axon terminal structure if OHT triggers early swelling or later atrophy. Future ultrastructural studies of the dLGN would be able to address this possibility. Notably, Smith and colleagues combined their measurements of axon terminal size with anterograde transport studies and found that areas of the SC with intact transport from the retina tended to have terminal swelling while areas deficient in transport (taken as a sign of poorer health) tended to have atrophied terminals (Smith et al., 2016). We did not perform transport experiments as part of this study. Doing so in combination with vGlut2 staining in future studies might reveal a similar pattern in the dLGN.

Although retinogeniculate (RG) synapses provide the major excitatory drive for TC neurons, they comprise only $\sim 10 \%$ of their total number of excitatory synaptic inputs (Bickford et al., 2010; Guido, 2018). The majority of excitatory inputs onto TC neurons are the result of corticothalamic (CT) synapses arising from layer VI of the visual cortex. These synapses function to modulate TC neuron responsiveness (Sherman and Guillery, 2002, 2011) and have a low release probability, as evidenced by their notable synaptic facilitation occurring during repeated stimulation (Turner and Salt, 1998; Jurgens et al., 2012). We find here that TC neurons from D2-control mice have a baseline mEPSC frequency of approximately $25 \mathrm{~Hz}$, which is similar to what we have shown previously in recordings at $\sim 30-33^{\circ} \mathrm{C}$ (Van Hook, 2020), although higher 
than mEPSC frequency detected in recordings at room temperature (Bhandari et al., 2019; Van Hook, 2020). In the current study, we found that mEPSC frequency recorded in TC neurons was reduced in both $4 \mathrm{~m}$ and $9 \mathrm{~m}$ D2 mice compared to their age-matched controls. The mechanisms underlying the reduced mEPSC frequency are unclear. IOP was not elevated in our sample of $4 \mathrm{~m}$ D2 mice, nor was mEPSC frequency correlated with IOP in 9m D2 mice, in contrast to electrophysiological markers of TC neuron excitability, vGlut2 loss, and RGC loss. RGC axonal transport, cytoskeleton, and energy homeostasis is disrupted at fairly young ages in D2 mice, and this is accompanied by morphological changes in RGC axon terminal mitochondria in the SC (Crish et al., 2010; Smith et al., 2016). Synaptic transmission requires ample energy supply and functioning mitochondria to handle vesicle recycling, regulation of presynaptic vesicle pool size and release probability, and presynaptic $\mathrm{Ca}^{2+}$ handling (Ly and Verstreken, 2006). Therefore, perturbations of RGC axon terminal mitochondria and axonal energy supply are likely to influence synaptic output and might contribute to our observed synaptic changes.

In a previous study using the microbead approach to induce OHT, we suggested that a similar reduction in mEPSC frequency might be attributable to a loss of post-synaptic TC neuron synapses, as evidenced by a reduction in TC neuron dendritic complexity (Bhandari et al., 2019). Dendritic atrophy in retinorecipient neurons in late-stage glaucoma has also been documented elsewhere, yet we have not yet tested whether or along what time course this occurs in D2 mice.

Alternatively, changes in mEPSC frequency might arise from changes to non-RGC inputs. Krahe \& Guido have shown that monocular deprivation leads to a homeostatic increase in synaptic input arising from the CT pathway in the dLGN (Krahe and Guido, 2011). They reached this conclusion from observing changes in short-term plasticity during CT tract stimulation and an increase in the proportion of detected mEPSCs with slower decay kinetics, which results from filtering of signals arising at distal dendritic sites (Williams and Mitchell, 2008). It remains to be seen what proportion of TC neuron mEPSCs arise from retinal vs. cortical sources and whether OHT and optic nerve pathology can influence CT synaptic function. CT innervation is shaped by RG inputs during development (Seabrook et al., 2013) and dysfunction and injury to RGC axons might re-awaken those developmental processes in adulthood (Nahmani and Turrigiano, 2014). However, we did not detect any changes in mEPSC kinetics at either 4m or $9 \mathrm{~m}$, arguing against up- or down-regulation of CT input. Given the loss of vGlut2-labeled RGC axon terminals in 9m D2 mice, it is likely that some reduction in mEPSC frequency is the result of less RGC input to each TC neuron at that time point, but not in $4 \mathrm{~m}$ mice, when vGlut2 labeling was unchanged compared to controls.

It will ultimately take examination of the properties of CT and RG synaptic function resulting from optic tract or $\mathrm{CT}$ tract stimulation to test for relative changes in synaptic function in D2 mice. We previously used optogenetic activation of RGC axons in microbead-injected mice to show that presynaptic vesicle release probability at RG synapses was increased in OHT (Bhandari et al., 2019). This was prior to substantial RGC degeneration or any detectable loss of vGlut2 staining in the dLGN, suggesting it might be an early, homeostatic response to pressure elevation. Numerous RGCs provide convergent synaptic input to each TC neuron, although only $\sim 3$ of those inputs are responsible the majority of excitatory drive to each cell (Chen and Regehr, 2000; Hammer et al., 2015; Litvina and Chen, 2017; Rompani et al., 2017). Given the IOP-associated decline in vGlut2 staining in 9m D2 mice, we do predict that later stages of 
627 disease will be characterized by a reduction in total RG synaptic strength, possibly as a 628 reduction in RGC convergence to each TC neuron, although the strength of inputs from single 629 fibers is likely to be diminished as well as axonal and synaptic function becomes more 630 compromised.

631 In conclusion, prior studies have documented numerous changes to the structure of

632 RGC axon terminals as well as to post-synaptic neurons in visual structures in the brain, 633 especially in the SC, at various time points in glaucoma. The findings in the current study shed 634 light on the progression of functional changes at the cellular and synaptic scale in the dLGN and 635 relate those changes to established markers of glaucomatous progression - namely IOP and 636 RGC loss in the retina. This study enhances the picture of disease progression and provides 637 important information linking the IOP to vision loss in glaucoma. 
641

642

643

644

645

646

647

648

649

650

651

652

653

654

655

656

657

658

659

660

661

662

663

664

665

666

667

668

669

670

671

672

673

674

675

\section{Bibliography}

Applebury, M. L., Antoch, M. P., Baxter, L. C., Chun, L. L., Falk, J. D., Farhangfar, F., et al. (2000). The murine cone photoreceptor: a single cone type expresses both $\mathrm{S}$ and $\mathrm{M}$ opsins with retinal spatial patterning. Neuron $27,513-523$.

Araújo, S. E. S., Mendonça, H. R., Wheeler, N. A., Campello-Costa, P., Jacobs, K. M., Gomes, F. C. A., et al. (2017). Inflammatory demyelination alters subcortical visual circuits. J. Neuroinflammation 14, 162. doi:10.1186/s12974-017-0936-0.

Bae, J. R., and Kim, S. H. (2017). Synapses in neurodegenerative diseases. BMB Rep. 50, 237246. doi:10.5483/BMBRep.2017.50.5.038.

Baltan, S., Inman, D. M., Danilov, C. A., Morrison, R. S., Calkins, D. J., and Horner, P. J. (2010). Metabolic vulnerability disposes retinal ganglion cell axons to dysfunction in a model of glaucomatous degeneration. J. Neurosci. Off. J. Soc. Neurosci. 30, 5644-5652. doi:10.1523/JNEUROSCI.5956-09.2010.

Bhandari, A., Smith, J. C., Zhang, Y., Jensen, A. A., Reid, L., Goeser, T., et al. (2019). Early-Stage Ocular Hypertension Alters Retinal Ganglion Cell Synaptic Transmission in the Visual Thalamus. Front. Cell. Neurosci. 13. doi:10.3389/fncel.2019.00426.

Bickford, M. E., Slusarczyk, A., Dilger, E. K., Krahe, T. E., Kucuk, C., and Guido, W. (2010). Synaptic development of the mouse dorsal lateral geniculate nucleus: Ultrastructure of Developing Mouse dLGN. J. Comp. Neurol. 518, 622-635. doi:10.1002/cne.22223.

Bracken, B. K., and Turrigiano, G. G. (2009). Experience-dependent regulation of TrkB isoforms in rodent visual cortex. Dev. Neurobiol. 69, 267-278. doi:10.1002/dneu.20701.

Calkins, D. J. (2012). Critical pathogenic events underlying progression of neurodegeneration in glaucoma. Prog. Retin. Eye Res. 31, 702-719. doi:10.1016/j.preteyeres.2012.07.001.

Calkins, D. J., Lambert, W. S., Formichella, C. R., McLaughlin, W. M., and Sappington, R. M. (2018). The Microbead Occlusion Model of Ocular Hypertension in Mice. Methods Mol. Biol. Clifton NJ 1695, 23-39. doi:10.1007/978-1-4939-7407-8_3.

Chen, C., and Regehr, W. G. (2000). Developmental remodeling of the retinogeniculate synapse. Neuron 28, 955-966.

Cohen-Cory, S., Kidane, A. H., Shirkey, N. J., and Marshak, S. (2010). Brain-derived neurotrophic factor and the development of structural neuronal connectivity. Dev. Neurobiol., NA-NA. doi:10.1002/dneu.20774.

Cooper, M. L., Crish, S. D., Inman, D. M., Horner, P. J., and Calkins, D. J. (2016). Early astrocyte redistribution in the optic nerve precedes axonopathy in the DBA/2J mouse model of glaucoma. Exp. Eye Res. 150, 22-33. doi:10.1016/j.exer.2015.11.016. 
676

677

678

679

680

681

682

683

684

685

686

687

688

689

690

691

692

693

694

695

696

697

698

699

700

701

702

703

704

705

706

707

708

709

710

Cooper, M. L., Pasini, S., Lambert, W. S., D’Alessandro, K. B., Yao, V., Risner, M. L., et al. (2020). Redistribution of metabolic resources through astrocyte networks mitigates neurodegenerative stress. Proc. Natl. Acad. Sci. 117, 18810-18821. doi:10.1073/pnas.2009425117.

Crish, S. D., and Calkins, D. J. (2015). Central visual pathways in glaucoma: evidence for distal mechanisms of neuronal self-repair. J. Neuro-Ophthalmol. Off. J. North Am. NeuroOphthalmol. Soc. 35 Suppl 1, S29-37. doi:10.1097/WNO.0000000000000291.

Crish, S. D., Dapper, J. D., MacNamee, S. E., Balaram, P., Sidorova, T. N., Lambert, W. S., et al. (2013). Failure of axonal transport induces a spatially coincident increase in astrocyte BDNF prior to synapse loss in a central target. Neuroscience 229, 55-70. doi:10.1016/j.neuroscience.2012.10.069.

Crish, S. D., Sappington, R. M., Inman, D. M., Horner, P. J., and Calkins, D. J. (2010). Distal axonopathy with structural persistence in glaucomatous neurodegeneration. Proc. Natl. Acad. Sci. U. S. A. 107, 5196-5201. doi:10.1073/pnas.0913141107.

Dekeyster, E., Geeraerts, E., Buyens, T., Van den Haute, C., Baekelandt, V., De Groef, L., et al. (2015). Tackling Glaucoma from within the Brain: An Unfortunate Interplay of BDNF and TrkB. PloS One 10, e0142067. doi:10.1371/journal.pone.0142067.

Della Santina, L., Inman, D. M., Lupien, C. B., Horner, P. J., and Wong, R. O. L. (2013). Differential progression of structural and functional alterations in distinct retinal ganglion cell types in a mouse model of glaucoma. J. Neurosci. Off. J. Soc. Neurosci. 33, 17444-17457. doi:10.1523/JNEUROSCI.5461-12.2013.

Dengler-Crish, C. M., Smith, M. A., Inman, D. M., Wilson, G. N., Young, J. W., and Crish, S. D. (2014). Anterograde transport blockade precedes deficits in retrograde transport in the visual projection of the DBA/2J mouse model of glaucoma. Front. Neurosci. 8, 290. doi:10.3389/fnins.2014.00290.

Desai, N. S., Rutherford, L. C., and Turrigiano, G. G. (1999). BDNF regulates the intrinsic excitability of cortical neurons. Learn. Mem. Cold Spring Harb. N 6, 284-291.

Dilger, E. K., Krahe, T. E., Morhardt, D. R., Seabrook, T. A., Shin, H.-S., and Guido, W. (2015). Absence of Plateau Potentials in dLGN Cells Leads to a Breakdown in Retinogeniculate Refinement. J. Neurosci. 35, 3652-3662. doi:10.1523/JNEUROSCI.2343-14.2015.

Domenici, L., Origlia, N., Falsini, B., Cerri, E., Barloscio, D., Fabiani, C., et al. (2014). Rescue of retinal function by BDNF in a mouse model of glaucoma. PloS One 9, e115579. doi:10.1371/journal.pone.0115579.

Dzyubenko, E., Rozenberg, A., Hermann, D. M., and Faissner, A. (2016). Colocalization of synapse marker proteins evaluated by STED-microscopy reveals patterns of neuronal 
synapse distribution in vitro. J. Neurosci. Methods 273, 149-159. doi:10.1016/j.jneumeth.2016.09.001.

Ecker, J. L., Dumitrescu, O. N., Wong, K. Y., Alam, N. M., Chen, S.-K., LeGates, T., et al. (2010). Melanopsin-expressing retinal ganglion-cell photoreceptors: cellular diversity and role in pattern vision. Neuron 67, 49-60. doi:10.1016/j.neuron.2010.05.023.

El-Danaf, R. N., Krahe, T. E., Dilger, E. K., Bickford, M. E., Fox, M. A., and Guido, W. (2015). Developmental remodeling of relay cells in the dorsal lateral geniculate nucleus in the absence of retinal input. Neural Develop. 10, 19. doi:10.1186/s13064-015-0046-6.

Frankfort, B. J., Khan, A. K., Tse, D. Y., Chung, I., Pang, J.-J., Yang, Z., et al. (2013). Elevated intraocular pressure causes inner retinal dysfunction before cell loss in a mouse model of experimental glaucoma. Invest. Ophthalmol. Vis. Sci. 54, 762-770. doi:10.1167/iovs.12-10581.

Guido, W. (2008). Refinement of the retinogeniculate pathway. J. Physiol. 586, 4357-4362. doi:10.1113/jphysiol.2008.157115.

Guido, W. (2018). Development, form, and function of the mouse visual thalamus. J. Neurophysiol. 120, 211-225. doi:10.1152/jn.00651.2017.

Gupta, N., Greenberg, G., de Tilly, L. N., Gray, B., Polemidiotis, M., and Yücel, Y. H. (2009). Atrophy of the lateral geniculate nucleus in human glaucoma detected by magnetic resonance imaging. Br. J. Ophthalmol. 93, 56-60. doi:10.1136/bjo.2008.138172.

Gupta, N., Ly, T., Zhang, Q., Kaufman, P. L., Weinreb, R. N., and Yücel, Y. H. (2007). Chronic ocular hypertension induces dendrite pathology in the lateral geniculate nucleus of the brain. Exp. Eye Res. 84, 176-184. doi:10.1016/j.exer.2006.09.013.

Gupta, N., and Yücel, Y. H. (2003). Brain changes in glaucoma. Eur. J. Ophthalmol. 13 Suppl 3, S32-35.

Gupta, V., You, Y., Li, J., Gupta, V., Golzan, M., Klistorner, A., et al. (2014). BDNF impairment is associated with age-related changes in the inner retina and exacerbates experimental glaucoma. Biochim. Biophys. Acta 1842, 1567-1578. doi:10.1016/j.bbadis.2014.05.026.

Hall, A. M., Throesch, B. T., Buckingham, S. C., Markwardt, S. J., Peng, Y., Wang, Q., et al. (2015). Tau-dependent Kv4.2 depletion and dendritic hyperexcitability in a mouse model of Alzheimer's disease. J. Neurosci. Off. J. Soc. Neurosci. 35, 6221-6230. doi:10.1523/JNEUROSCI.2552-14.2015.

Hammer, S., Monavarfeshani, A., Lemon, T., Su, J., and Fox, M. A. (2015). Multiple Retinal Axons Converge onto Relay Cells in the Adult Mouse Thalamus. Cell Rep. 12, 1575-1583. doi:10.1016/j.celrep.2015.08.003. 
Hong, Y. K., and Chen, C. (2011). Wiring and rewiring of the retinogeniculate synapse. Curr. Opin. Neurobiol. 21, 228-237. doi:10.1016/j.conb.2011.02.007.

Hooks, B. M., and Chen, C. (2006). Distinct roles for spontaneous and visual activity in remodeling of the retinogeniculate synapse. Neuron 52, 281-291. doi:10.1016/j.neuron.2006.07.007.

Howell, G. R., Libby, R. T., Marchant, J. K., Wilson, L. A., Cosma, I. M., Smith, R. S., et al. (2007). Absence of glaucoma in DBA/2J mice homozygous for wild-type versions of Gpnmb and Tyrp1. BMC Genet. 8, 45. doi:10.1186/1471-2156-8-45.

Inman, D. M., and Harun-Or-Rashid, M. (2017). Metabolic Vulnerability in the Neurodegenerative Disease Glaucoma. Front. Neurosci. 11, 146. doi:10.3389/fnins.2017.00146.

Inman, D. M., Sappington, R. M., Horner, P. J., and Calkins, D. J. (2006). Quantitative correlation of optic nerve pathology with ocular pressure and corneal thickness in the DBA/2 mouse model of glaucoma. Invest. Ophthalmol. Vis. Sci. 47, 986-996. doi:10.1167/iovs.05-0925.

Jassim, A. H., Coughlin, L., Harun-Or-Rashid, M., Kang, P. T., Chen, Y.-R., and Inman, D. M. (2019). Higher Reliance on Glycolysis Limits Glycolytic Responsiveness in Degenerating Glaucomatous Optic Nerve. Mol. Neurobiol. 56, 7097-7112. doi:10.1007/s12035-0191576-4.

John, S. W., Smith, R. S., Savinova, O. V., Hawes, N. L., Chang, B., Turnbull, D., et al. (1998). Essential iris atrophy, pigment dispersion, and glaucoma in DBA/2J mice. Invest. Ophthalmol. Vis. Sci. 39, 951-962.

Jurgens, C. W. D., Bell, K. A., McQuiston, A. R., and Guido, W. (2012). Optogenetic stimulation of the corticothalamic pathway affects relay cells and GABAergic neurons differently in the mouse visual thalamus. PloS One 7, e45717. doi:10.1371/journal.pone.0045717.

Kerschensteiner, D., and Guido, W. (2017). Organization of the dorsal lateral geniculate nucleus in the mouse. Vis. Neurosci. 34, E008. doi:10.1017/S0952523817000062.

Kim, J., Hughes, E. G., Shetty, A. S., Arlotta, P., Goff, L. A., Bergles, D. E., et al. (2017). Changes in the Excitability of Neocortical Neurons in a Mouse Model of Amyotrophic Lateral Sclerosis Are Not Specific to Corticospinal Neurons and Are Modulated by Advancing Disease. J. Neurosci. 37, 9037-9053. doi:10.1523/JNEUROSCI.0811-17.2017.

Krahe, T. E., and Guido, W. (2011). Homeostatic plasticity in the visual thalamus by monocular deprivation. J. Neurosci. Off. J. Soc. Neurosci. 31, 6842-6849. doi:10.1523/JNEUROSCI.1173-11.2011. 
778

779

780

781

782

783

784

785

786

787

788

789

790

791

792

793

794

795

796

797

798

799

800

801

802

803

804

805

806

807

808

809

810

811

812

Krahe, T. E., Seabrook, T. A., Chen, C.-K. J., Fox, M. A., and Guido, W. (2012). Modulation of CREB in the Dorsal Lateral Geniculate Nucleus of Dark-Reared Mice. Neural Plast. 2012, 1-8. doi:10.1155/2012/426437.

Lambo, M. E., and Turrigiano, G. G. (2013). Synaptic and intrinsic homeostatic mechanisms cooperate to increase L2/3 pyramidal neuron excitability during a late phase of critical period plasticity. J. Neurosci. Off. J. Soc. Neurosci. 33, 8810-8819. doi:10.1523/JNEUROSCI.4502-12.2013.

Liang, L., and Chen, C. (2020). Organization, Function, and Development of the Mouse Retinogeniculate Synapse. Annu. Rev. Vis. Sci. 6, 261-285. doi:10.1146/annurev-vision121219-081753.

Libby, R. T., Anderson, M. G., Pang, I.-H., Robinson, Z. H., Savinova, O. V., Cosma, I. M., et al. (2005). Inherited glaucoma in DBA/2J mice: pertinent disease features for studying the neurodegeneration. Vis. Neurosci. 22, 637-648. doi:10.1017/S0952523805225130.

Litvina, E. Y., and Chen, C. (2017). Functional Convergence at the Retinogeniculate Synapse. Neuron 96, 330-338.e5. doi:10.1016/j.neuron.2017.09.037.

Liu, M., Duggan, J., Salt, T. E., and Cordeiro, M. F. (2011). Dendritic changes in visual pathways in glaucoma and other neurodegenerative conditions. Exp. Eye Res. 92, 244-250. doi:10.1016/j.exer.2011.01.014.

Liu, M., Guo, L., Salt, T. E., and Cordeiro, M. F. (2014). Dendritic changes in rat visual pathway associated with experimental ocular hypertension. Curr. Eye Res. 39, 953-963. doi:10.3109/02713683.2014.884594.

Louros, S. R., Hooks, B. M., Litvina, L., Carvalho, A. L., and Chen, C. (2014). A role for stargazin in experience-dependent plasticity. Cell Rep. 7, 1614-1625. doi:10.1016/j.celrep.2014.04.054.

Ly, C. V., and Verstreken, P. (2006). Mitochondria at the Synapse. The Neuroscientist 12, 291299. doi:10.1177/1073858406287661.

Madisen, L., Mao, T., Koch, H., Zhuo, J., Berenyi, A., Fujisawa, S., et al. (2012). A toolbox of Credependent optogenetic transgenic mice for light-induced activation and silencing. Nat. Neurosci. 15, 793-802. doi:10.1038/nn.3078.

Maffei, A., and Turrigiano, G. G. (2008). Multiple Modes of Network Homeostasis in Visual Cortical Layer 2/3. J. Neurosci. 28, 4377-4384. doi:10.1523/JNEUROSCI.5298-07.2008.

Marshak, S., Nikolakopoulou, A. M., Dirks, R., Martens, G. J., and Cohen-Cory, S. (2007). CellAutonomous TrkB Signaling in Presynaptic Retinal Ganglion Cells Mediates Axon Arbor Growth and Synapse Maturation during the Establishment of Retinotectal Synaptic Connectivity. J. Neurosci. 27, 2444-2456. doi:10.1523/JNEUROSCI.4434-06.2007. 
McGrady, N. R., Risner, M. L., Vest, V., and Calkins, D. J. (2020). TRPV1 Tunes Optic Nerve Axon Excitability in Glaucoma. Front. Physiol. 11. doi:10.3389/fphys.2020.00249.

Nahmani, M., and Turrigiano, G. G. (2014). Adult cortical plasticity following injury: Recapitulation of critical period mechanisms? Neuroscience 283, 4-16. doi:10.1016/j.neuroscience.2014.04.029.

Nikolakopoulou, A. M., Meynard, M. M., Marshak, S., and Cohen-Cory, S. (2010). Synaptic maturation of the Xenopus retinotectal system: Effects of brain-derived neurotrophic factor on synapse ultrastructure. J. Comp. Neurol. 518, 972-989. doi:10.1002/cne.22258.

Orr, B. O., Hauswirth, A. G., Celona, B., Fetter, R. D., Zunino, G., Kvon, E. Z., et al. (2020). Presynaptic Homeostasis Opposes Disease Progression in Mouse Models of ALS-Like Degeneration: Evidence for Homeostatic Neuroprotection. Neuron 107, 95-111.e6. doi:10.1016/j.neuron.2020.04.009.

Ou, Y., Jo, R. E., Ullian, E. M., Wong, R. O. L., and Della Santina, L. (2016). Selective Vulnerability of Specific Retinal Ganglion Cell Types and Synapses after Transient Ocular Hypertension. J. Neurosci. Off. J. Soc. Neurosci. 36, 9240-9252. doi:10.1523/JNEUROSCI.0940-16.2016.

Pang, J.-J., Frankfort, B. J., Gross, R. L., and Wu, S. M. (2015). Elevated intraocular pressure decreases response sensitivity of inner retinal neurons in experimental glaucoma mice. Proc. Natl. Acad. Sci. U. S. A. 112, 2593-2598. doi:10.1073/pnas.1419921112.

Pham, T. A., Rubenstein, J. L. R., Silva, A. J., Storm, D. R., and Stryker, M. P. (2001). The CRE/CREB Pathway Is Transiently Expressed in Thalamic Circuit Development and Contributes to Refinement of Retinogeniculate Axons. Neuron 31, 409-420. doi:10.1016/S0896-6273(01)00381-6.

Risner, M. L., McGrady, N. R., Pasini, S., Lambert, W. S., and Calkins, D. J. (2020). Elevated ocular pressure reduces voltage-gated sodium channel NaV1.2 protein expression in retinal ganglion cell axons. Exp. Eye Res. 190, 107873. doi:10.1016/j.exer.2019.107873.

Risner, M. L., Pasini, S., Cooper, M. L., Lambert, W. S., and Calkins, D. J. (2018). Axogenic mechanism enhances retinal ganglion cell excitability during early progression in glaucoma. Proc. Natl. Acad. Sci. U. S. A. 115, E2393-E2402. doi:10.1073/pnas.1714888115.

Rodriguez, A. R., de Sevilla Müller, L. P., and Brecha, N. C. (2014). The RNA binding protein RBPMS is a selective marker of ganglion cells in the mammalian retina. J. Comp. Neurol. 522, 1411-1443. doi:10.1002/cne.23521.

Rompani, S. B., Müllner, F. E., Wanner, A., Zhang, C., Roth, C. N., Yonehara, K., et al. (2017). Different Modes of Visual Integration in the Lateral Geniculate Nucleus Revealed by 

Single-Cell-Initiated Transsynaptic Tracing. Neuron 93, 767-776.e6. doi:10.1016/j.neuron.2017.01.028.

Rose, T., and Bonhoeffer, T. (2018). Experience-dependent plasticity in the lateral geniculate nucleus. Curr. Opin. Neurobiol. 53, 22-28. doi:10.1016/j.conb.2018.04.016.

Rutherford, L. C., Nelson, S. B., and Turrigiano, G. G. (1998). BDNF has opposite effects on the quantal amplitude of pyramidal neuron and interneuron excitatory synapses. Neuron $21,521-530$.

Sappington, R. M., Carlson, B. J., Crish, S. D., and Calkins, D. J. (2010). The microbead occlusion model: a paradigm for induced ocular hypertension in rats and mice. Invest. Ophthalmol. Vis. Sci. 51, 207-216. doi:10.1167/iovs.09-3947.

Seabrook, T. A., Burbridge, T. J., Crair, M. C., and Huberman, A. D. (2017). Architecture, Function, and Assembly of the Mouse Visual System. Annu. Rev. Neurosci. 40, 499-538. doi:10.1146/annurev-neuro-071714-033842.

Seabrook, T. A., El-Danaf, R. N., Krahe, T. E., Fox, M. A., and Guido, W. (2013). Retinal input regulates the timing of corticogeniculate innervation. J. Neurosci. Off. J. Soc. Neurosci. 33, 10085-10097. doi:10.1523/JNEUROSCI.5271-12.2013.

Sherman, S. M., and Guillery, R. W. (2002). The role of the thalamus in the flow of information to the cortex. Philos. Trans. R. Soc. Lond. B. Biol. Sci. 357, 1695-1708. doi:10.1098/rstb.2002.1161.

Sherman, S. M., and Guillery, R. W. (2011). Distinct functions for direct and transthalamic corticocortical connections. J. Neurophysiol. 106, 1068-1077. doi:10.1152/jn.00429.2011.

Sladek, A. L., and Nawy, S. (2020). Ocular Hypertension Drives Remodeling of AMPA Receptors in Select Populations of Retinal Ganglion Cells. Front. Synaptic Neurosci. 12, 30. doi:10.3389/fnsyn.2020.00030.

Smith, M. A., Xia, C. Z., Dengler-Crish, C. M., Fening, K. M., Inman, D. M., Schofield, B. R., et al. (2016). Persistence of intact retinal ganglion cell terminals after axonal transport loss in the DBA/2J mouse model of glaucoma. J. Comp. Neurol. 524, 3503-3517. doi:10.1002/cne.24012.

Sommeijer, J.-P., Ahmadlou, M., Saiepour, M. H., Seignette, K., Min, R., Heimel, J. A., et al. (2017). Thalamic inhibition regulates critical-period plasticity in visual cortex and thalamus. Nat. Neurosci. 20, 1715-1721. doi:10.1038/s41593-017-0002-3.

Sondereker, K. B., Stabio, M. E., Jamil, J. R., Tarchick, M. J., and Renna, J. M. (2018). Where You Cut Matters: A Dissection and Analysis Guide for the Spatial Orientation of the Mouse Retina from Ocular Landmarks. J. Vis. Exp. doi:10.3791/57861. 
Stabio, M. E., Sondereker, K. B., Haghgou, S. D., Day, B. L., Chidsey, B., Sabbah, S., et al. (2018). A novel map of the mouse eye for orienting retinal topography in anatomical space. J. Comp. Neurol. 526, 1749-1759. doi:10.1002/cne.24446.

Ting, J. T., Daigle, T. L., Chen, Q., and Feng, G. (2014). Acute brain slice methods for adult and aging animals: application of targeted patch clamp analysis and optogenetics. Methods Mol. Biol. Clifton NJ 1183, 221-242. doi:10.1007/978-1-4939-1096-0_14.

Ting, J. T., Lee, B. R., Chong, P., Soler-Llavina, G., Cobbs, C., Koch, C., et al. (2018). Preparation of Acute Brain Slices Using an Optimized N-Methyl-D-glucamine Protective Recovery Method. J. Vis. Exp. JoVE. doi:10.3791/53825.

Turner, J. P., and Salt, T. E. (1998). Characterization of sensory and corticothalamic excitatory inputs to rat thalamocortical neurones in vitro. J. Physiol. 510 ( Pt 3), 829-843.

Turrigiano, G. (2011). Too Many Cooks? Intrinsic and Synaptic Homeostatic Mechanisms in Cortical Circuit Refinement. Annu. Rev. Neurosci. 34, 89-103. doi:10.1146/annurevneuro-060909-153238.

Turrigiano, G. (2012). Homeostatic Synaptic Plasticity: Local and Global Mechanisms for Stabilizing Neuronal Function. Cold Spring Harb. Perspect. Biol. 4, a005736-a005736. doi:10.1101/cshperspect.a005736.

Valiente-Soriano, F. J., Nadal-Nicolás, F. M., Salinas-Navarro, M., Jiménez-López, M., BernalGarro, J. M., Villegas-Pérez, M. P., et al. (2015). BDNF Rescues RGCs But Not Intrinsically Photosensitive RGCs in Ocular Hypertensive Albino Rat Retinas. Invest. Ophthalmol. Vis. Sci. 56, 1924-1936. doi:10.1167/iovs.15-16454.

Van Hook, M. J. (2020). Temperature effects on synaptic transmission and neuronal function in the visual thalamus. PLOS ONE 15, e0232451. doi:10.1371/journal.pone.0232451.

Wang, A. L., Carroll, R. C., and Nawy, S. (2014). Down-regulation of the RNA editing enzyme ADAR2 contributes to RGC death in a mouse model of glaucoma. PloS One 9, e91288. doi:10.1371/journal.pone.0091288.

Wang, H.-L., Xian, X.-H., Song, Q.-Y., Pang, C., Wang, J.-L., Wang, M.-W., et al. (2017). Agerelated alterations of neuronal excitability and voltage-dependent Ca2+ current in a spontaneous mouse model of Alzheimer's disease. Behav. Brain Res. 321, 209-213. doi:10.1016/j.bbr.2017.01.009.

Wang, X., Zhang, X.-G., Zhou, T.-T., Li, N., Jang, C.-Y., Xiao, Z.-C., et al. (2016). Elevated Neuronal Excitability Due to Modulation of the Voltage-Gated Sodium Channel Nav1.6 by A $\beta 1-42$. Front. Neurosci. 10, 94. doi:10.3389/fnins.2016.00094.

Weinreb, R. N., Aung, T., and Medeiros, F. A. (2014). The pathophysiology and treatment of glaucoma: a review. JAMA 311, 1901-1911. doi:10.1001/jama.2014.3192. 
919 Williams, S. R., and Mitchell, S. J. (2008). Direct measurement of somatic voltage clamp errors in central neurons. Nat. Neurosci. 11, 790-798. doi:10.1038/nn.2137.

921 Wilson, G. N., Smith, M. A., Inman, D. M., Dengler-Crish, C. M., and Crish, S. D. (2016). Early Cytoskeletal Protein Modifications Precede Overt Structural Degeneration in the DBA/2J Mouse Model of Glaucoma. Front. Neurosci. 10. doi:10.3389/fnins.2016.00494.

924 Wishart, T. M., Parson, S. H., and Gillingwater, T. H. (2006). Synaptic Vulnerability in Neurodegenerative Disease. J. Neuropathol. Exp. Neurol. 65, 733-739. doi:10.1097/01.jnen.0000228202.35163.c4.

927 Wondolowski, J., and Dickman, D. (2013). Emerging links between homeostatic synaptic plasticity and neurological disease. Front. Cell. Neurosci. 7. doi:10.3389/fncel.2013.00223. neurons in magno- and parvocellular layers in the lateral geniculate nucleus in experimental glaucoma. Invest. Ophthalmol. Vis. Sci. 42, 3216-3222. 


\section{Figure Legends}

Figure 1 - Eye pressure is elevated in DBA/2J mice. $A \& B$ ) Intraocular pressure (IOP) measurements from $D B A / 2 J^{G n m m b+/ S j J}$ (D2-control, $A$ ) mice $(n=62$ eyes from 31 mice) and $\mathrm{DBA} / 2 \mathrm{~J}(\mathrm{D} 2, \mathrm{~B})$ mice $(\mathrm{n}=66$ eyes from 33 mice). C) Histogram of peak IOP values obtained from D2 and D2-control mice. D2-control IOPs were narrowly distributed (median $=14 \mathrm{mmHg}$ ) while the peak IOPs from D2 mice showed a broader distribution (median $=23 \mathrm{mmHg}$ ).

Figure 2 - Enhancement of TC neuron spiking in D2 mice. A) Left, microscopy image of dLGN with patch-clamp electrode in coronal brain slice. Right, higher magnification image showing a TC neuron with patch clamp electrode. B) Evoked spiking responses to depolarizing current injection (+120 and $+320 \mathrm{pA})$ and voltage deflections to hyperpolarizing current injections (-20 and $-80 \mathrm{pA}$ ) in $4 \mathrm{~m}$ D2 mice ( 15 cells, 5 mice) and D2-control mice ( $n=15$ cells, 5 mice). C) Plot of current injection and counts of evoked spikes (mean \pm SEM) show that TC neurons from $4 \mathrm{~m}$ D2 mice fired more spikes ( ${ }^{*} p<0.05$, unpaired t-test). D) Spiking and hyperpolarizing voltage responses from 9m D2-control and D2 mice. E) Similar to panel C, TC neurons from 9m D2 mice ( $n=23$ cells, 6 mice) were slightly more excitable than from D2-control mice ( $n=13$ cells, 4 mice). F) Mean \pm SD of the area under the curve of spiking responses and data points from individual cells from $4 \mathrm{~m}$ and $9 \mathrm{~m}$ D2 and D2-control mice. Significance was assessed using a nested t-test approach. G) Mean \pm SD and individual cell data points of the half-maximal current injection from a Boltzmann fit to the current-spiking relationships. $H$ ) There was no significant correlation of AUC or $\mathrm{I}_{50}$ with IOP (measured at $4 \mathrm{~m}$ of age) as assessed with a linear regression for $4 \mathrm{~m}$ D2 mice. Regression was performed on mean values of AUC and $I_{50}$ for each mouse rather than on individual cells. I) In 9m D2 mice, there was a significant correlation of $A U C$ and $I_{50}$ with a three-month cumulative IOP averaged across two eyes for each mouse.

Figure 3 - Changes to passive membrane properties support enhanced TC neuron excitability in D2 mice. A\&B) Plots of voltage deflection evoked by hyperpolarizing current injections in $4 \mathrm{~m}$ (A) and 9m (B) D2-control and D2 mice. In D2 mice, hyperpolarizing current injections evoked larger voltage changes $\left({ }^{*} p<0.05\right.$, unpaired t-test). C) Resting membrane potential (Vrest) measured in D2 and D2-control mice at $9 \mathrm{~m}$ and $4 \mathrm{~m}$. Vrest was significantly depolarized in $4 \mathrm{~m}$ D2 mice, but not 9m D2 mice when compared with age-matched controls (nested t-test). Input resistance (Rin), measured using a linear fit to voltage deflections evoked by -20 and -40 pA, was significantly elevated in 4m D2 TC neurons, but not for $9 \mathrm{~m}$ when compared using a nested t-test. E) Membrane capacitance was not significantly different between D2-control and D2 mice at $4 \mathrm{~m}$ or $9 \mathrm{~m}$ (nested t-test). F) There was no significant correlation of Vrest, Rin, or $\mathrm{Cm}$ with IOP at $4 \mathrm{~m}$ as assessed using a linear regression. G) Although there was no significant correlation of Vrest in 9m D2 TC neurons with the 3-month cumulative IOP, Rin and Cm did correlate in a manner that supports enhanced TC neuron excitability in D2 mice with elevated IOP.

Figure 4 - Measurement of TC neuron soma size in 4m and 9m D2 mice. 50 micron dLGN sections were stained using a NeuN primary antibody to label neurons while a GAD65/67 antibody was used to identify and exclude GABAergic interneurons. A\&C) After imaging, TC 
neuron somata were traced. Lower panels show the somatic outlines (yellow). B) At 4m, TC neurons were slightly smaller in D2 mice $(n=106$ cells from 4 mice, compared to D2-controls ( $n$ $=214$ cells from 6 mice), although the difference did not pass our significance threshold for the $\mathrm{K}-\mathrm{S}$ test $(\mathrm{p}=0.00055)$. At $9 \mathrm{~m}$, there was a significant leftward shift in the distribution of TC neuron soma size in D2 mice ( $n=321$ cells from 9 mice) compared to D2-controls ( $n=312$ cells from 10 mice; $p<0.00001, \mathrm{~K}-\mathrm{S}$ test).

Figure 5 - IOP elevation in the microbead model enhances dLGN TC neuron excitability. A) Following bilateral anterior chamber injection of 10-micron polystyrene microbeads, IOP was elevated by $\sim 5 \mathrm{mmHg}$ ( $\mathrm{n}=10$ eyes from 5 mice) compared to saline-injected control mice $(\mathrm{n}=$ 18 eyes from 9 mice; ${ }^{*} p<0.05$, unpaired t-test). B) Whole-cell current clamp recordings from TC neurons in dLGN coronal slices show spiking and hyperpolarizing voltage responses to depolarizing (+180 pA) and hyperpolarizing (-20, -70, and -220 pA) current injections in TC neurons from saline-and bead-injected mice. C) Plot of mean \pm SEM of current-evoked spiking $\left({ }^{*} p<0.05\right.$, unpaired t-test). Saline data are from 38 cells from 9 mice while microbead data are from 23 cells from 5 mice. D) AUC was significantly elevated in cells from bead-injected mice compared to saline-injected controls (nested t-test). $I_{50}$ was slightly reduced, although not significantly. Bars and errors bars show mean \pm SD while data points are measurements from individual cells. E) There was no significant correlation of AUC or $I_{50}$ with IOP from bead-injected mice as assessed with a linear regression. Cumulative $\triangle I O P$ represents the between-eyes average of IOP measurements taken at 1 week, 2 weeks, and 4 weeks post-injection. F) Voltage responses to hyperpolarizing current injections were used to measure passive membrane properties from the same population of cells. G) TC neurons from bead-injected mice were slightly depolarized relative to saline-injected controls (nested t-test). Rin was significantly elevated and $\mathrm{Cm}$ was not significantly different. $\mathrm{H}$ ) Passive membrane properties did not significantly correlate with IOP as assessed with a linear regression.

Figure 6 - mEPSC frequency was reduced in D2 mice. A) Whole-cell voltage clamp records of mEPSCs recorded in the absence of stimulation for $4 m$ D2-control ( $n=12$ cells from 5 mice) and D2 mice ( $n=11$ cells from 4 mice). Single events are the average of events detected in each cell. B) Mean \pm SD of mEPSC frequency was slightly reduced in 4m D2 mice. Individual points show the average instantaneous frequency for all events from individual cells. The difference was not statistically significant when assessed with a nested t-test, although there was a slight leftward shift in the distribution of inter-event intervals that was significant when assessed with a K-S test. C) mESPC amplitude was not different between $4 \mathrm{~m}$ D2-controls and D2 mice. D) mEPSCs recorded from TC neurons from 9m D2-control $(n=15$ cells from 4 mice) and D2 mice $(n=18$ cells from 6 mice). E) mEPSC frequency was reduced at $9 \mathrm{~m}$. F) mEPSC amplitude was similar in D2-control and D2 TC neurons at $9 \mathrm{~m}$.

Figure 7 - vGlut2-labeled RGC axon terminals are lost in an IOP-dependent manner in 9m D2 mice. A) 2.5-micron-thick maximum intensity projections of vGlut2 staining from the dLGN core of $4 \mathrm{~m} \mathrm{D2-control} \mathrm{(} n=6$ mice) and D2 mice ( $n=4$ mice). B) Neither density nor size of detected vGlut2 puncta was significantly different between D2-control and D2 mice at $4 \mathrm{~m}$. C) vGlut2 images from 9m D2-control ( $n=10$ mice) and D2 mice ( $n=10$ mice). For D2 mice, images are 
1024

1025

1026

1027

1028

1029

1030

1031

1032

1033

1034

1035

1036

1037

1038

1039

1040

1041

1042

1043

1044

1045

shown from mice with higher vGlut2 density (middle panel) and lower vGlut2 density (right panel) to illustrate the range of labeling seen. D) vGlut2 density is significantly reduced in $9 \mathrm{~m}$ D2 mice compared to D2-controls (unpaired t-test) while vGlut2 puncta size is not different. E) vGlut2 density in 9m D2 mice dLGN sections significantly correlated with the three-month cumulative IOP as assessed with a linear regression.

Figure 8 - RBPMS-stained retinal ganglion cells are lost in an IOP-dependent manner in 9m D2 mice. A) Immunofluorescence images from RBPMS-stained retinas from a $4 \mathrm{~m}$ D2-control and a D2 mouse show similar RBPMS+ RGC soma density. B) Quantification of RBPMS+ cell bodies in four quadrants of central and peripheral retina. Density was slightly higher in 4m D2 mice (8 retinas from 4 mice) compared to $D 2$-control mice ( $n=7$ retinas from 4 mice) in central retina $(* p<0.05$, unpaired t-test). Bars and error bars represent mean \pm SD while individual points are RGC density measurements from individual retinas. C) RBPMS images from 9m D2-control (left) and D2 mouse retinas (center and right). Images from 9m D2 retinas with higher and lower RBPMS+ cell density are shown to illustrate the diversity of RGC densities seen in D2 mice. D) RBPMS+ cell density was lower in all four quadrants of central and peripheral retinas of 9m D2 mice ( $n=19$ retinas from 12 mice) compared to D2-controls ( $n=12$ retinas from 7 mice) illustrates the diversity of RGC survival from mouse-to-mouse. Bars and error bars represent mean \pm SD while individual data points are RGC survival in individual retinas. E) Quantification of RGC survival across the entire retina at $9 \mathrm{~m}$. F) RGC survival significantly correlated with the three-month cumulative IOP in 9m D2 mice, as assessed using a linear regression. 
bioRxiv preprint doi: https://doi.org/10.1101/2020.10.23.352310; this version posted October 25, 2020. The copyright holder for this preprint (which was not certified by peer review) is the author/funder. All rights reserved. No reuse allowed without permission.

Figure 1

1047

1048

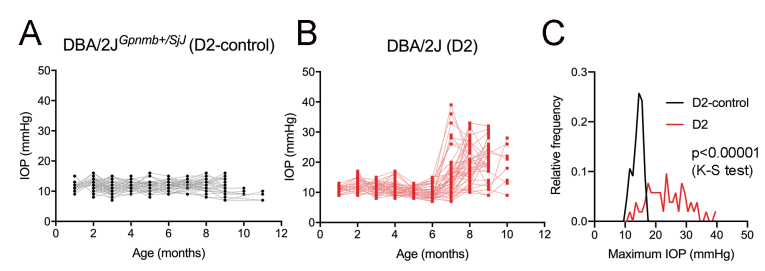


Figure 2
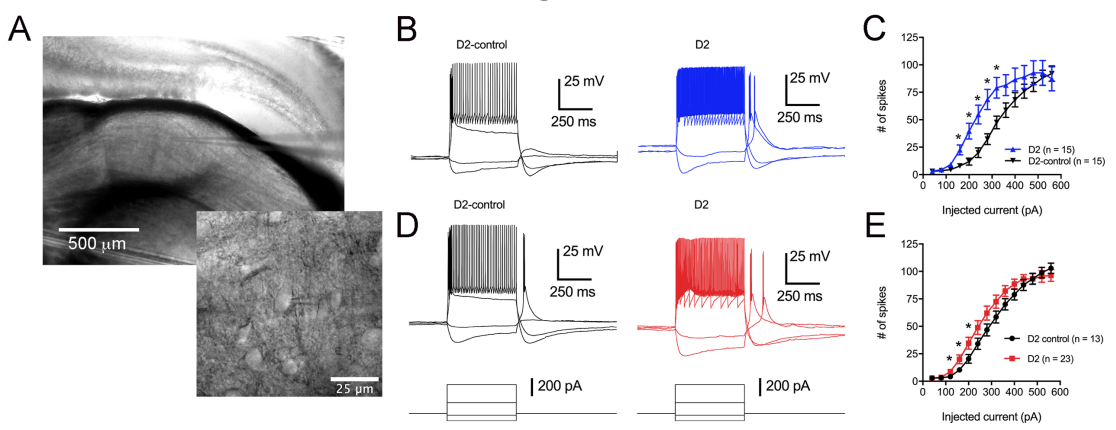

E
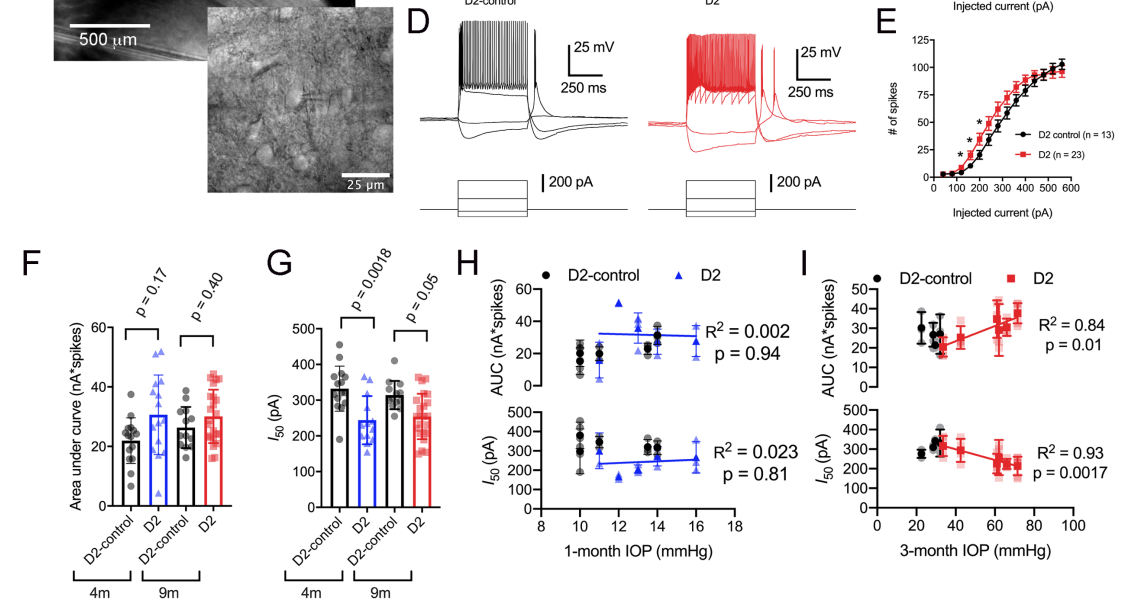

1051

1052

1053 


\section{Figure 3}

A

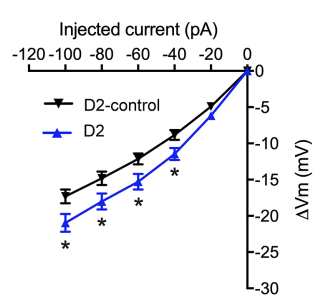

B
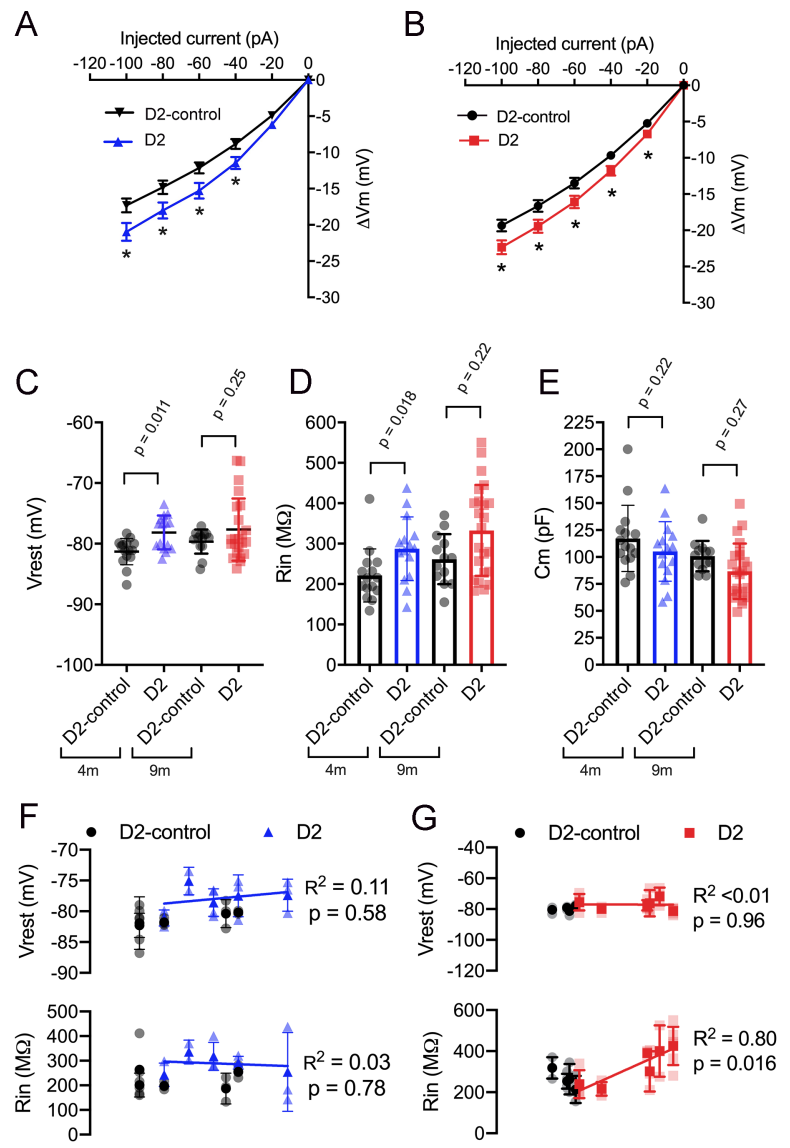

1055
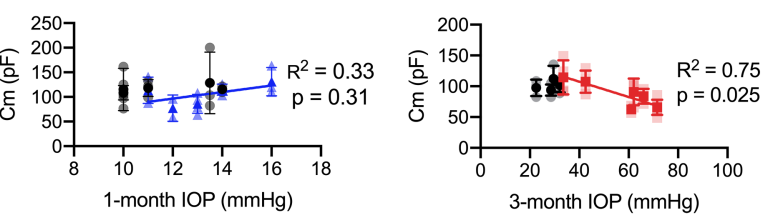
bioRxiv preprint doi: https://doi.org/10.1101/2020.10.23.352310; this version posted October 25, 2020. The copyright holder for this preprint (which was not certified by peer review) is the author/funder. All rights reserved. No reuse allowed without permission.

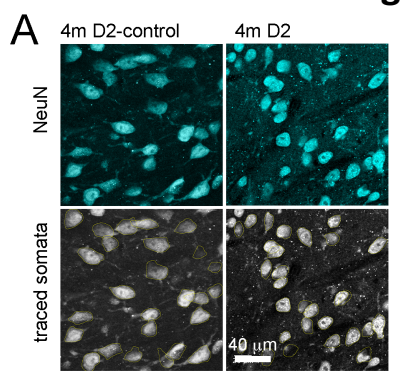

Figure 4

B

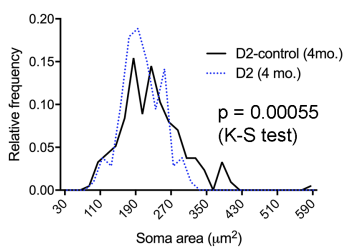

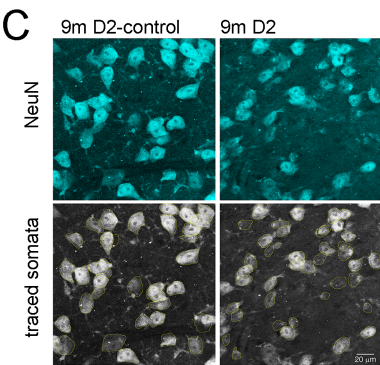

D

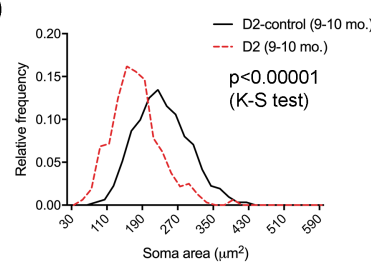

Figure 5

A

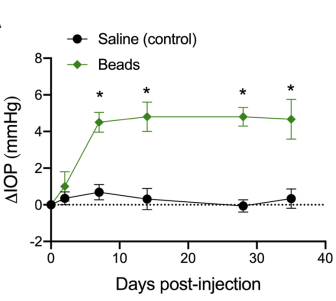

C

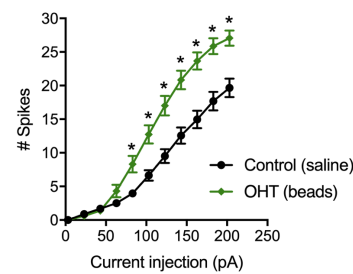

F

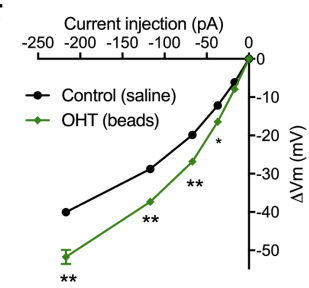

$\mathrm{H}$

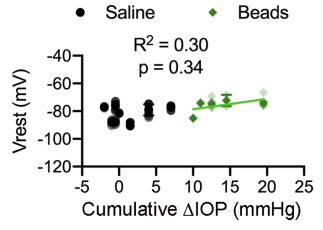

B Control (saline)

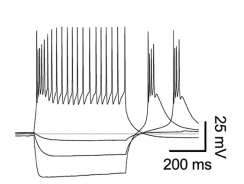

5 wks OHT (beads)

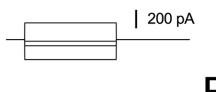

E
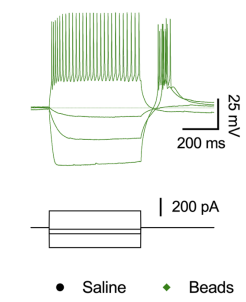

D

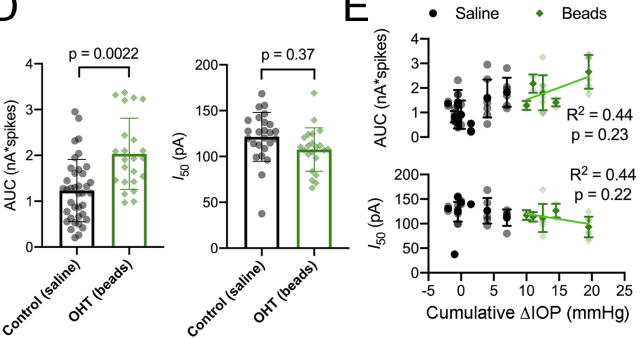

G
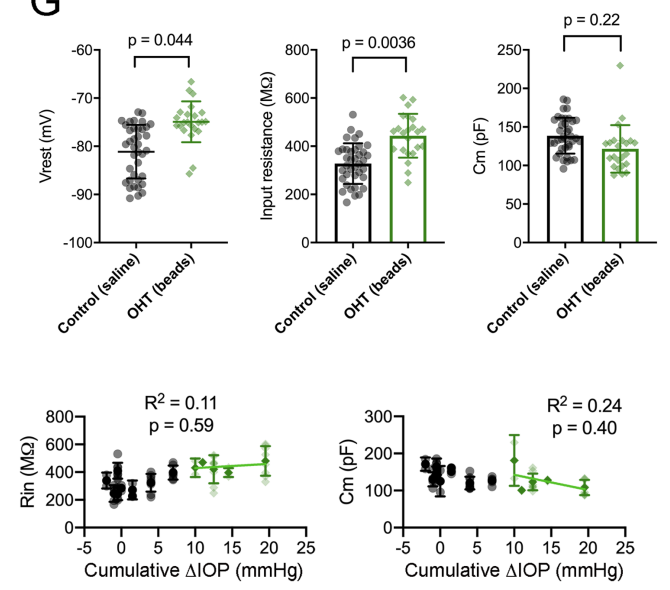


\section{Figure 6}

A D2-control (4 mo.)

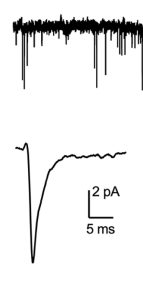

D2 (4 mo.)

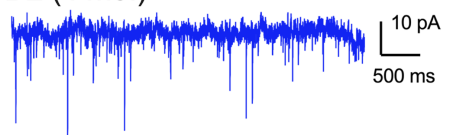

$\sqrt{\frac{L^{2 \mathrm{pA}}}{\mathrm{ms}}}$

D D2-control (9-10 mo)
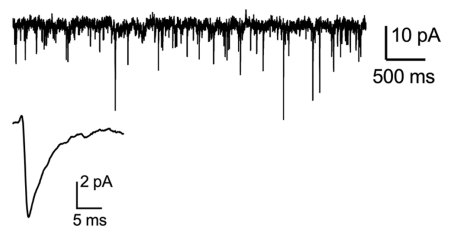

D2 (9-10 mo)
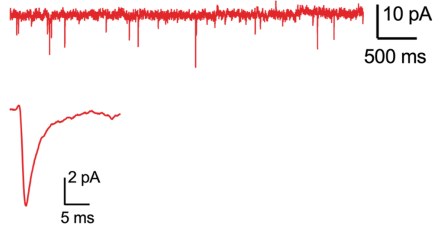

B

C
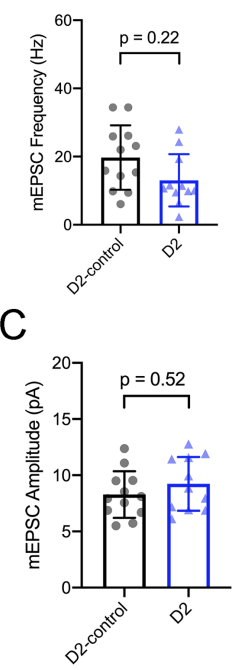

$\mathrm{E}$

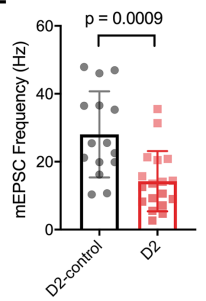

$\mathrm{F}$

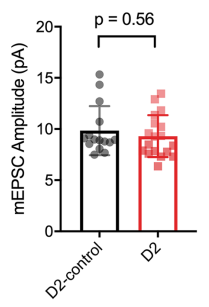

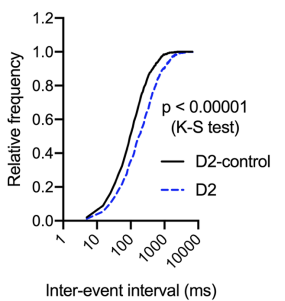

Inter-event interval (ms)
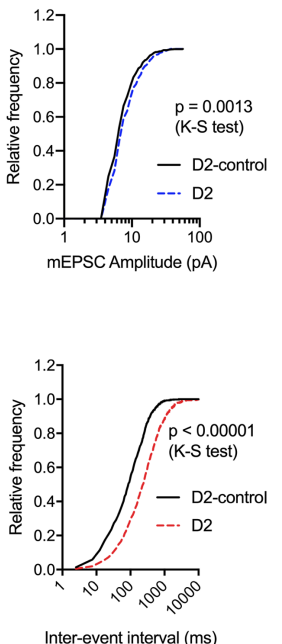

Inter-event interval (ms)

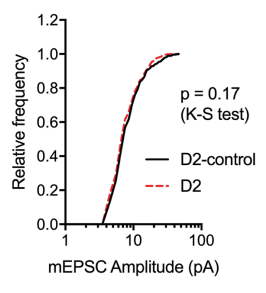


bioRxiv preprint doi: https://doi.org/10.1101/2020.10.23.352310; this version posted October 25, 2020. The copyright holder for this preprint (which was not certified by peer review) is the author/funder. All rights reserved. No reuse allowed without permission.

1066

Figure 7

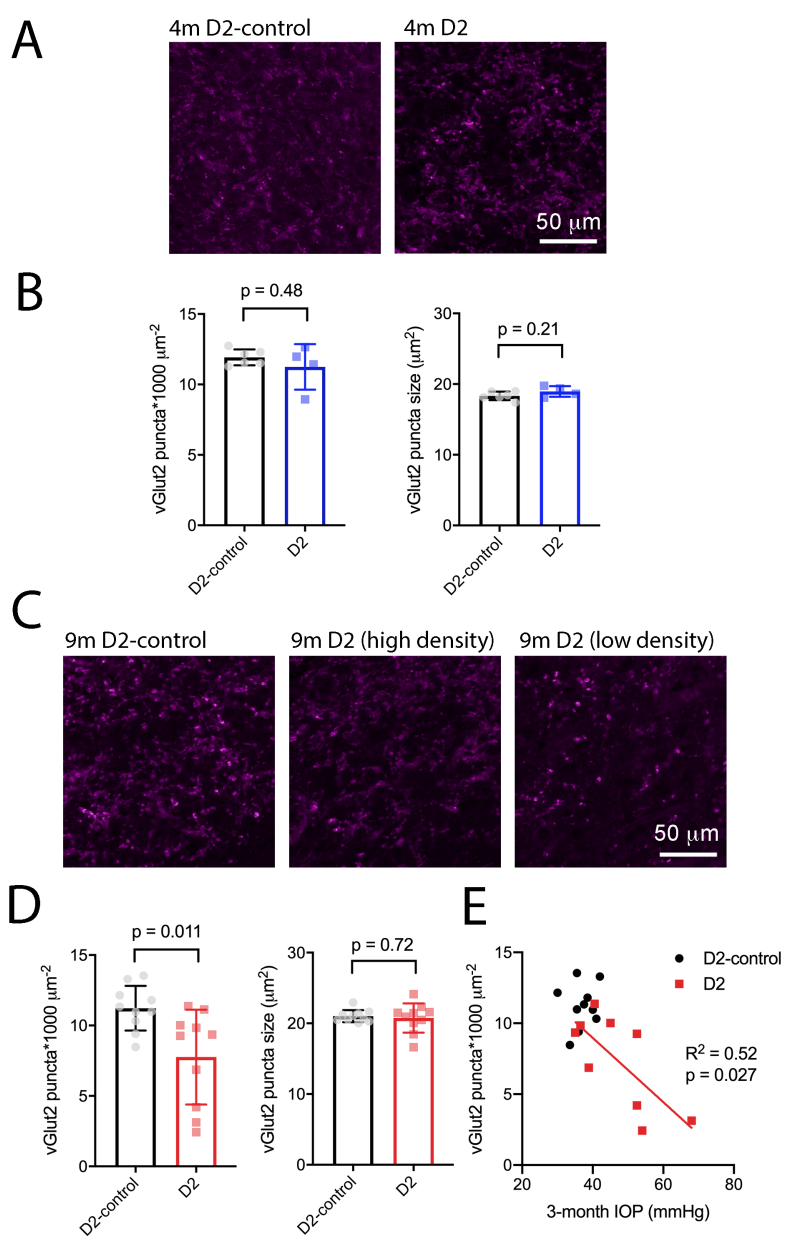


Figure 8

A
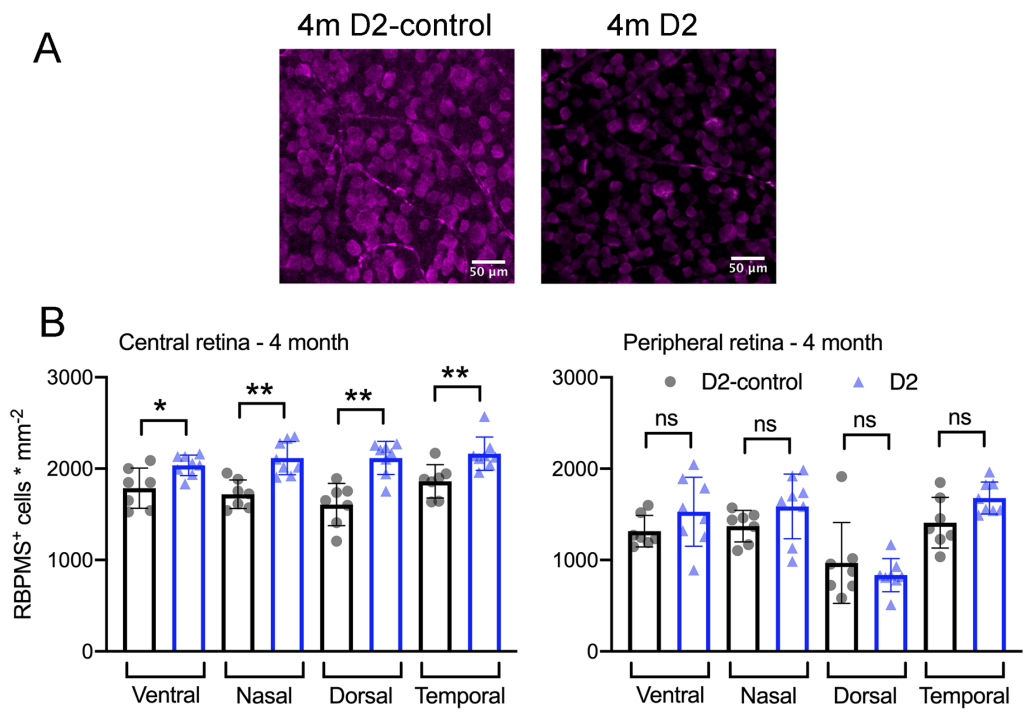

C

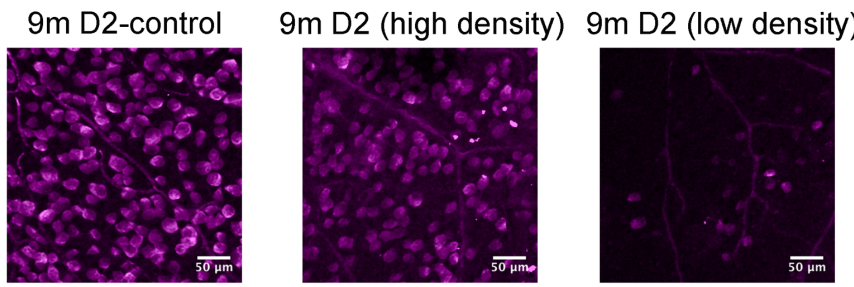

D

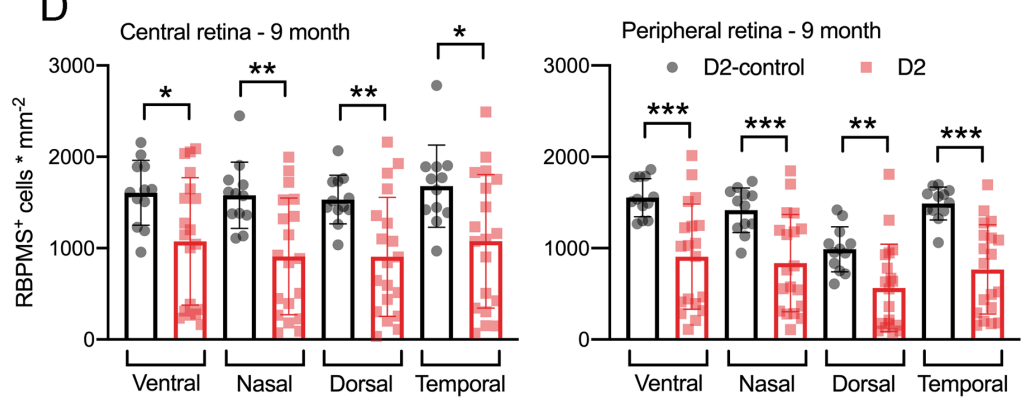

E

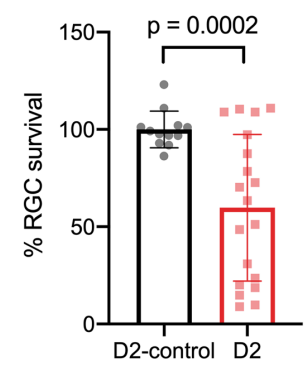

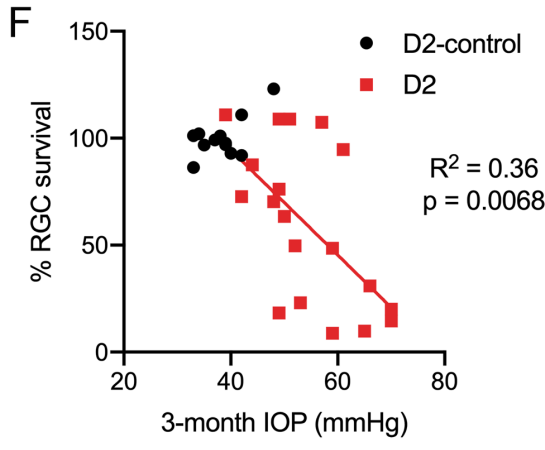

